\title{
Advanced maturation of human cardiac tissue grown from pluripotent stem cells
}

\author{
Kacey Ronaldson-Bouchard ${ }^{1}$, Stephen P. Ma ${ }^{1}$, Keith Yeager ${ }^{1}$, Timothy Chen ${ }^{1}$, LouJin Song ${ }^{2}$, Dario Sirabella ${ }^{1}$, Kumi Morikawa ${ }^{2}$, \\ Diogo Teles ${ }^{1,3,4}$, Masayuki Yazawa ${ }^{2} \&$ Gordana Vunjak-Novakovic ${ }^{1,5 *}$
}

\begin{abstract}
Cardiac tissues generated from human induced pluripotent stem cells (iPSCs) can serve as platforms for patient-specific studies of physiology and disease $\mathrm{e}^{1-6}$. However, the predictive power of these models is presently limited by the immature state of the cells ${ }^{1,2,5,6}$. Here we show that this fundamental limitation can be overcome if cardiac tissues are formed from early-stage iPSC-derived cardiomyocytes soon after the initiation of spontaneous contractions and are subjected to physical conditioning with increasing intensity over time. After only four weeks of culture, for all iPSC lines studied, such tissues displayed adult-like gene expression profiles, remarkably organized ultrastructure, physiological sarcomere length $(2.2 \mu \mathrm{m})$ and density of mitochondria $(30 \%)$, the presence of transverse tubules, oxidative metabolism, a positive force-frequency relationship and functional calcium handling. Electromechanical properties developed more slowly and did not achieve the stage of maturity seen in adult human myocardium. Tissue maturity was necessary for achieving physiological responses to isoproterenol and recapitulating pathological hypertrophy, supporting the utility of this tissue model for studies of cardiac development and disease.
\end{abstract}

Even the best available methods have limited ability to emulate the physiology of adult myocardium ${ }^{1-12}$; excitation-contraction coupling (requiring transverse tubules (T-tubules)), positive forcefrequency relationship (requiring mature calcium handling) and efficient energy conversion (requiring oxidative metabolism) are notably absent ${ }^{2,3,5,6,8-10}$. Adult ventricular myocytes are uniquely organized for beating function, having densely packed sarcomeres, mitochondria, transverse tubules and sarcoplasmic or endoplasmic reticulum (SR/ER). Their mitochondria are positioned adjacent to sarcomeres and calcium pumps to enhance ATP diffusion; the sarcoplasmic reticulum provides fast delivery of stored calcium ions to contractile proteins; and the T-tubules synchronize heartbeats by concentrating L-type calcium channels, which are positioned close to the ryanodine receptors that release calcium ions from the SR/ER ${ }^{13}$. This highly specialized machinery for excitation-contraction coupling is not present in the fetal heart, but emerges after birth ${ }^{14}$ with the switch from glycolytic to oxidative metabolism that supports the energy demands of the postnatal heart ${ }^{15}$.

Human iPSC-derived cardiomyocytes (hiPS-CMs) can be matured by long-term culture and electrical, hydrodynamic and mechanical stimulation ${ }^{8,9,12,16-18}$. Recent studies have indicated that this in vitro maturation may not follow the in vivo developmental paradigm; high stimulation frequencies benefit maturation in vitro ${ }^{9}$, whereas the native heart beats more slowly following birth ${ }^{5,14}$. We investigated the reasons why current strategies fail to develop the characteristics of adult myocardium. Because the responsiveness of hiPS-CMs to physical stimuli declines as differentiation progresses, we suggested that electromechanical conditioning should be initiated early, during the period of high cell plasticity. As the heart matures in response to energy demands, we further hypothesized that increasing the intensity of induced contractions would enhance the development of mature ultrastructure and function.
To test these hypotheses, we studied the maturation of human cardiac tissues grown from early-stage hiPS-CMs (day 12, immediately following the first spontaneous contractions) or late-stage hiPS-CMs (day 28, matured in culture). Cardiac tissues were assembled in a modular tissue platform that enabled individual control of the culture environment and physical signalling. hiPS-CMs (derived from three donors) and supporting fibroblasts were incorporated into fibrin hydrogel stretched between two flexible pillars (designed to provide mechanical forces similar to those in native myocardium) and subjected to electrical stimulation to induce auxotonic contractions. Three conditioning regimes were applied: (i) control (no stimulation); (ii) constant (three weeks at $2 \mathrm{~Hz}$ ); and (iii) intensity training (two weeks at a frequency increasing from $2 \mathrm{~Hz}$ to $6 \mathrm{~Hz}$ by $0.33 \mathrm{~Hz}$ per day, followed by one week at $2 \mathrm{~Hz}$. The resulting tissues were $6 \mathrm{~mm}$ long and $1.8 \mathrm{~mm}$ in diameter, and were evaluated in real time (for contractile and conductive behaviour and calcium handling) and by end-point assays (for gene expression, proteins and ultrastructure), using human fetal cardiac tissues (FCTs) and adult human heart ventricles as benchmarks (Fig. 1a, Extended Data Fig. 1a-e). Intensity-trained tissues grown from early-stage hiPS-CMs (hereafter early-stage intensity-trained) exhibited compact and well-differentiated cardiac muscle (Extended Data Fig. 1f-p) and marked changes in the expression of genes associated with adult-like conduction (increased ITPR3, KCNH2, decreased HCN4), maturation (increased $N P P B, M A P K 1, P R K A C A$ ), ultrastructure (increased $M Y H 7$, GJA1, TNNI3, AKAP6, GJA5, JPH2), energetics (increased AKAP1, TFAM, PPARGC1A) and calcium handling (increased CAV3, BIN1, ATP2A2, RYR2, ITPR3). The other early-stage-derived tissues, all latestage-derived tissues and FCTs displayed immature cardiac phenotypes (Fig. 1b, Extended Data Fig. 2a, b).

Seeding with early-stage hiPS-CMs was critical for the response of the mature tissues to physical signals. Only the early-stage intensitytrained tissues displayed orderly signal propagation and anisotropic gap junctions. Among all tested groups, early-stage intensity-trained tissues had electrophysiological properties that were comparable to Biowires ${ }^{9}$, including the shape of the action potential with its characteristic notch, the resting membrane potential of $-70.0 \pm 2.7 \mathrm{mV}$, the $I_{\mathrm{K} 1}$ current (peak inward density of $-9.9 \pm 3.8 \mathrm{pA} \mathrm{pF}^{-1}$ and peak outward density of $0.30 \pm 0.12 \mathrm{pA} \mathrm{pF}^{-1}$ ) and the conduction velocity $\left(25.0 \pm 0.9 \mathrm{~cm} \mathrm{~s}^{-1}\right.$ ) (Fig. 1c, d, Extended Data Figs. 2, 3a-f, Supplementary Videos 1,2).

Early-stage intensity-trained tissues also exhibited a positive forcefrequency relationship (FFR), a hallmark of maturation not seen in other in vitro myocardial tissue model $s^{5,6}$. The generated forces markedly exceeded those in all other tested groups and FCT (Fig. 1f), but remained below those in adult myocardium ${ }^{19}\left(44 \mathrm{mN} \mathrm{mm}^{-2}\right)$. Directly measured forces and contraction amplitudes increased approximately twofold over the range of stimulation frequencies $(1-6 \mathrm{~Hz})$ during the maturation of early-stage intensity-trained tissues, indicating the maturation of contractile behaviour. These tissues acquired regular contraction profiles, in contrast to late-stage intensity-trained tissues

\footnotetext{
${ }^{1}$ Laboratory for Stem Cells and Tissue Engineering, Department of Biomedical Engineering, Columbia University, New York, NY, USA. ${ }^{2}$ Department of Rehabilitation and Regenerative Medicine, Department of Pharmacology, College of Physicians and Surgeons, Columbia University, New York, NY, USA. ${ }^{3}$ Life and Health Sciences Research Institute (ICVS), School of Medicine, University of Minho, Braga, Portugal. ${ }^{4}$ ICVS/3B's, PT Government Associate Laboratory, Braga-Guimarães, Portugal. ${ }^{5}$ Department of Medicine, Columbia University, New York, NY, USA. *e-mail: gv2131@ columbia.edu
} 
a
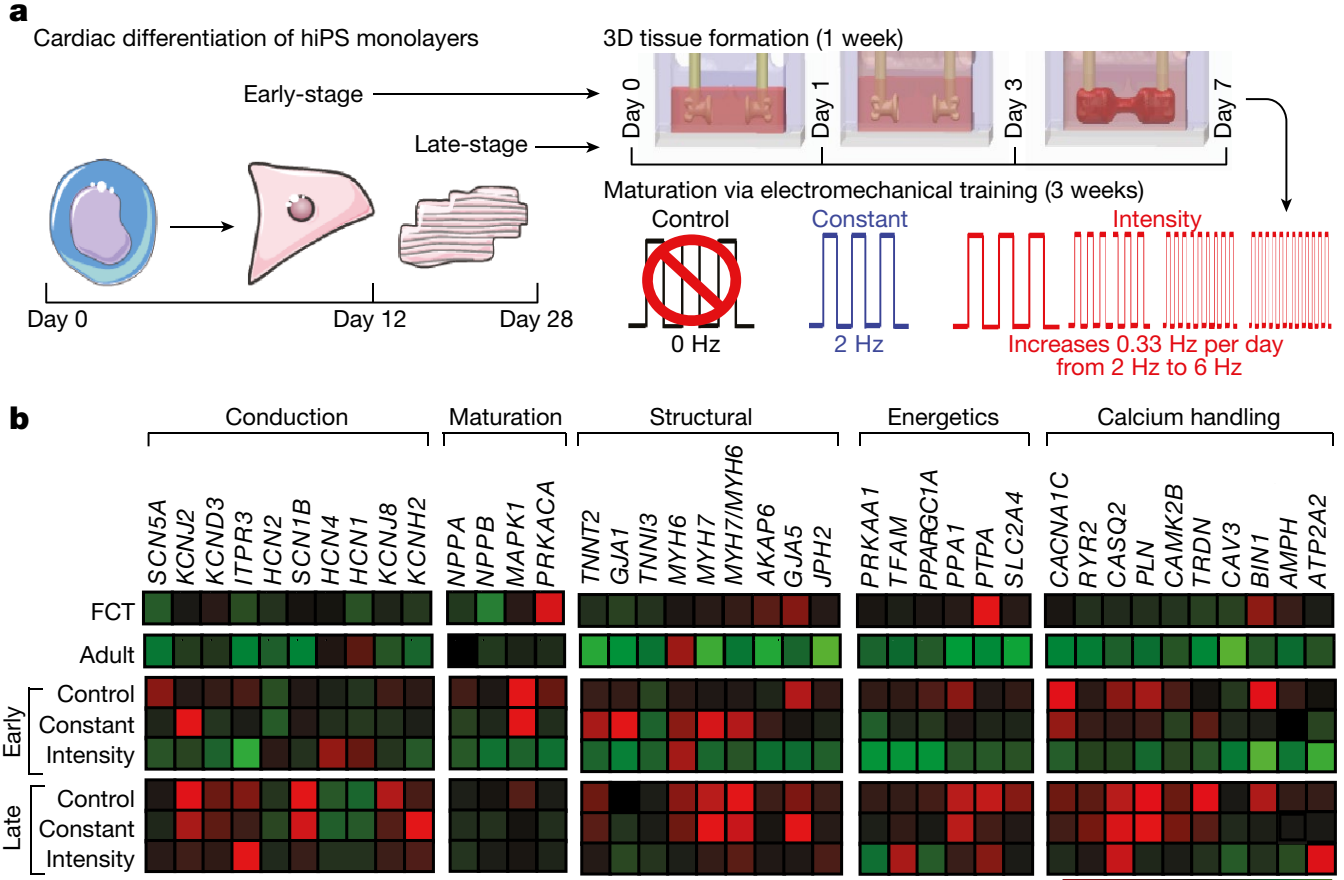

Calcium handling
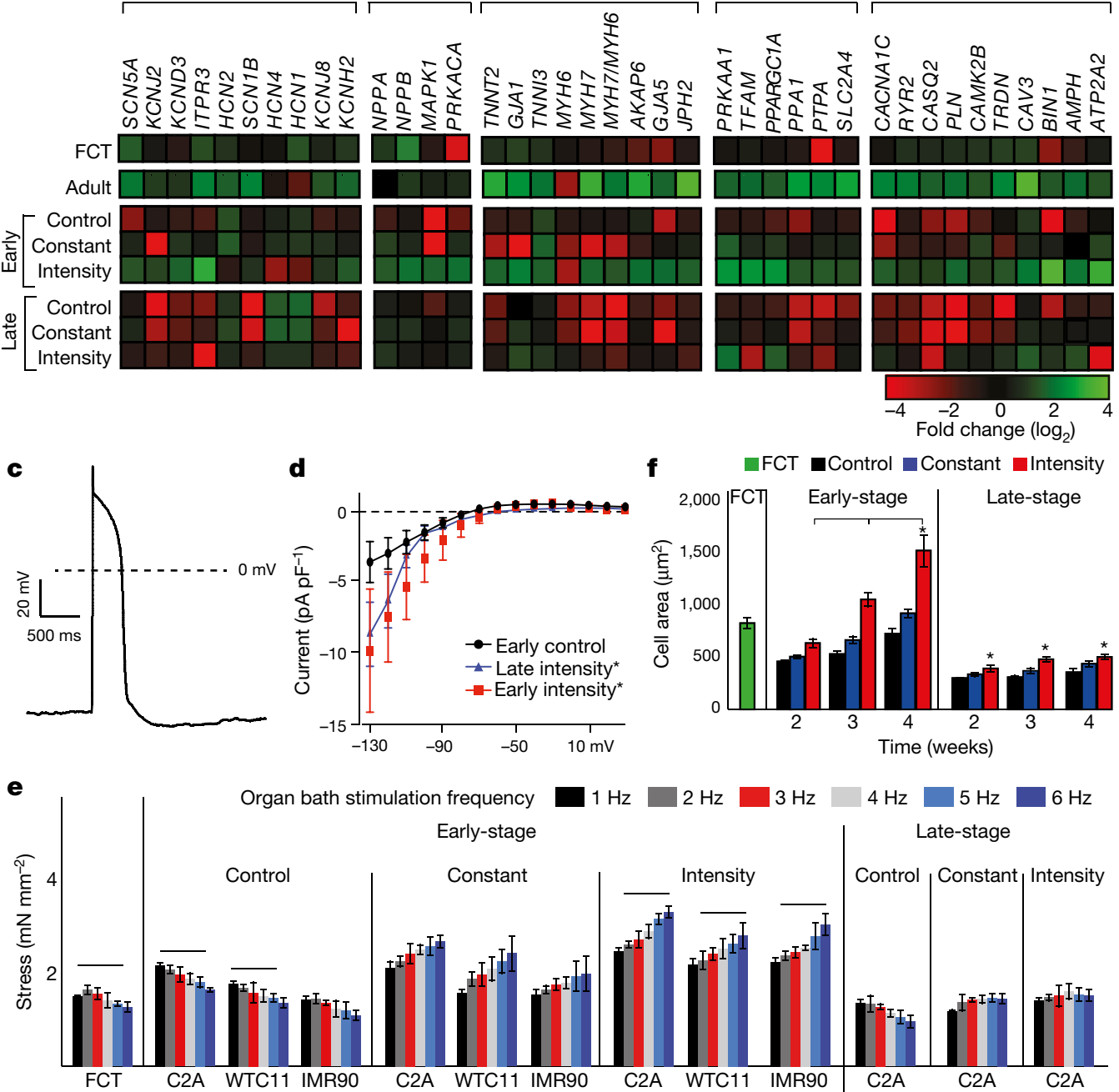

Fig. 1 Intensity training of cardiac tissues derived from early-stage hiPS-CMs enhances maturation. a, Experimental design: early-stage or late-stage hiPS-CMs and supporting fibroblasts were encapsulated in fibrin hydrogel to form tissues stretched between two elastic pillars and made to contract by electrical stimulation. Gradual increase in frequency of stimulation to supra-physiological levels (intensity regime) was compared to stimulation at constant frequency (constant regime), unstimulated controls and human adult and fetal heart ventricles. b, Gene expression data for six groups of cardiac tissues, and adult and fetal heart ventricles. c, Action potential for the early-stage intensity-trained group. d, $I_{\mathrm{K} 1}$ current-voltage $(I-V)$ curves (mean \pm s.d.). e, Early-stage

(Extended Data Figs. 3g-i, 4a-d, Supplementary Videos 1, 2). The surrogate measurements of force from calcium recordings in early-stage intensity-trained tissues (Extended Data Fig. 3j, k), were consistent with the direct force measurements.

Cell populations were dominated by cardiomyocytes, and the MLC2 $\mathrm{v}^{+}: \mathrm{MLC} \mathrm{a}^{+}$ratio, an indicator of cardiomyocyte maturity, depended on the stimulation regime and developmental stage of
Cell line

intensity-trained tissues from all three iPSC lines (C2A, WTC11, IMR90), but not the other groups, developed a positive force-frequency relationship after four weeks of culture. Line above graph indicates $P<0.05$ for the $2-6 \mathrm{~Hz}$ group versus other training regimes using two-way ANOVA followed by Tukey's honest significant difference (HSD) test. f, Cell area over time. Line above graph indicates $P<0.05$ versus other timepoints using two-way ANOVA followed by Tukey's HSD test; $* P<0.05$ versus control group using one-way ANOVA followed by Tukey's HSD test. Data in $\mathbf{e}$ and $\mathbf{f}$ are mean $\pm 95 \%$ confidence interval (CI). Sample sizes are shown in Supplementary Information, 'Main figure data sample sizes'.

hiPS-CMs. The increasing contractile demands induced the adult-like cardiac morphology that is necessary for high force generation in earlystage intensity-trained tissues. The cell size increased (an indicator of physiological hypertrophy ${ }^{8}$ ) and both cells and nuclei were elongated (an indicator of maturation ${ }^{8}$ ). The sarcomere length reached $2.2 \mu \mathrm{m}$, a similar value to that of adult human ventricular myocytes ${ }^{8}$. The contractile capacity, fraction of cells containing sarcomeres and 
a

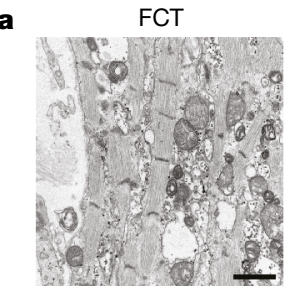

b

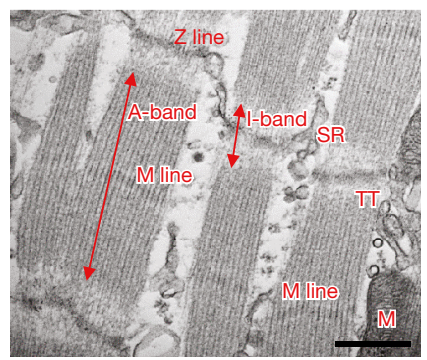

Control

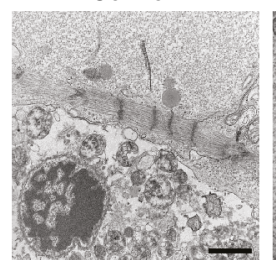

c

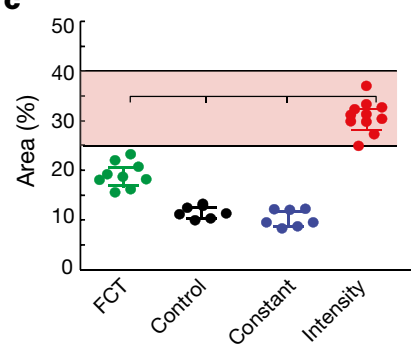

Intensity
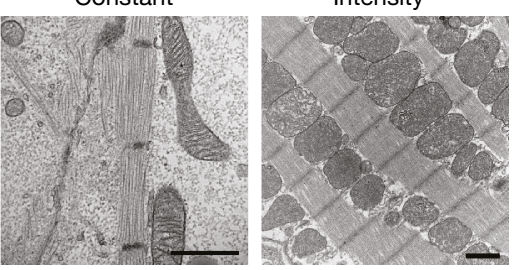

Adult

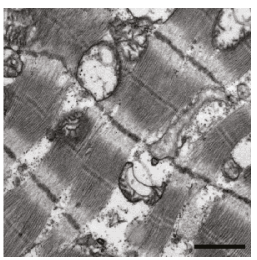

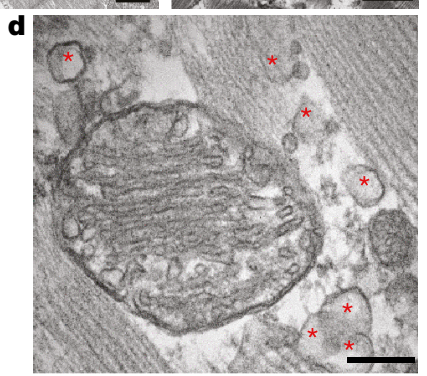
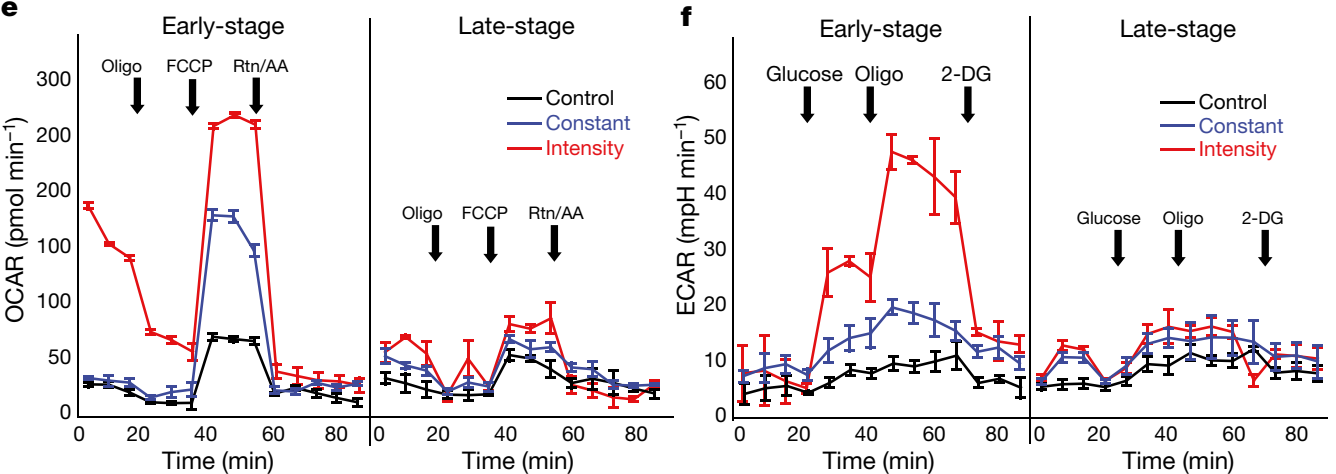
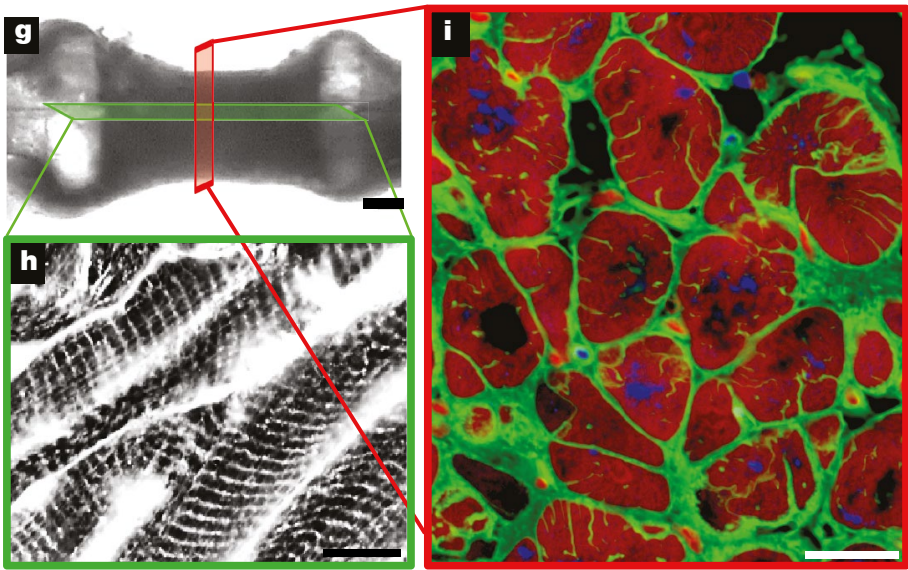

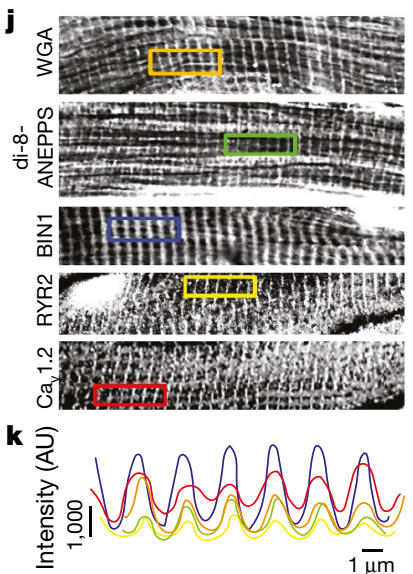

Fig. 2 Enhanced cardiac ultrastructure, bioenergetics and T-tubule formation in early-stage intensity-trained tissues derived from C2A cells. a, Transmission electron microscopy (TEM) of tissues and cardiac tissue models. Scale bars, $1 \mu \mathrm{m}$. b, d, $\mathbf{g}-\mathbf{k}$, Early-stage intensity-trained tissues cultured for four weeks and derived from C2A cells. b, Registers of sarcomeres, showing A-bands, I-bands, $\mathrm{M}$ lines, $\mathrm{Z}$ lines, sarcoplasmic reticulum (SR) and T-tubules (TT). Scale bar, $1 \mu \mathrm{m}$. c, Density of mitochondria; shaded area represents range of values measured in adult human heart. Line above graph indicates $P<0.05$ versus other training regimes using two-way ANOVA followed by Tukey's HSD test. d, Lipid droplets (red asterisk). Scale bar, $1 \mu \mathrm{m}$. e, Oxygen consumption rate (OCR). Oligo, oligomycin; FCCP, carbonyl cyanide-4-(trifluoromethoxy) phenylhydrazone; Rtn/AA, rotenone and antimycin A. f, Extracellular acidification rate. 2-DG, 2-deoxyglucose. $\mathbf{g}$-i, Cross-sections taken to evaluate T-tubules: bright field view (g; scale bar, $500 \mu \mathrm{m})$; T-tubules (h, i; green, WGA; red, cardiac troponin T (cTnT); blue, nuclei; scale bar, $10 \mu \mathrm{m})$. j, Calcium handling ultrastructure. Scale bar, $15 \mu \mathrm{m}$. k, Regular spacing of calcium handling proteins shown in $\mathbf{j}$. AU, arbitrary units. Data are mean $\pm 95 \%$ CI; sample sizes are shown in Supplementary organization of sarcomeric $\alpha$-actinin also resembled those of adult human myocardium (Fig. 1e, Extended Data Figs. 4e-k, 5).

Ultrastructural development was dependent on the stimulation regime and the developmental stage of hiPS-CMs from which the tissues were derived. Only early-stage intensity-trained tissues displayed orderly registers of sarcomeres with I-bands, A-bands, M lines, Z lines, desmosomes, intercalated discs, a high density of mitochondria positioned adjacent to the contractile machinery and proteins organized for increased energetics (Fig. 2a, b, Extended Data Figs. 6, 7a, b).

Whereas the fetal heart favours glucose as the primary energy substrate $^{19}$, the increased workload in the postnatal heart results in mature mitochondria that are optimized for fatty acid oxidation ${ }^{20,21}$. The per cent area of mitochondria in early-stage intensity-trained tissues ( $30 \pm 2.9 \%)$ was similar to those measured in adult human myocardium ${ }^{22,23}$. Active 
biogenesis ${ }^{24}$ was associated with the production of phospholipids near the sarcomeres, a switch to oxidative metabolism and the formation of T-tubules (Fig. 2c-f, Extended Data Fig. 7c, d).

Early-stage intensity-trained tissues contained robust T-tubules, both longitudinally and in cross-sections. T-tubules (measured using wheat germ agglutinin (WGA) and di-8-ANEPPS) were co-localized with the bridging integrator 1 (BIN1), ryanodine receptor 2 (RYR2), and L-type calcium channels $\left(\mathrm{Ca}_{\mathrm{V}} 1.2\right.$, encoded by CACNA1C) with spacing optimized for calcium handling (Fig. 2g-k, Extended Data Fig. 8), as in the adult heart ${ }^{25}$. These tissues displayed spatially uniform cell densities, presumably owing to the enhanced transport of nutrients and metabolites during tissue contractions, generated the highest force, and expressed the $\mathrm{Ca}^{2+}$-induced $\mathrm{Ca}^{2+}$ release (CICR) modulators RYR2 (control of SR/ER calcium release) and BIN1 (control of ion flux along T-tubules ${ }^{26}$ ) (Fig. 3a, Extended Data Figs. 8a, f, g, 9a).

The frequency-dependent acceleration of relaxation (FDAR), an intrinsic property of adult myocardium that was observed for earlystage intensity-trained tissues showed that the tissues subjected to supra-threshold electrical pacing regimes developed mechanisms to respond to the increasing workload. The presence of ultrastructural machinery for contraction-relaxation was confirmed by the positioning of T-tubules in proximity to the cardiac calcium pump SERCA2A (encoded by ATP2A2) and the sodium-calcium exchanger NCX1 (encoded by SLC8A1). Consistently, transcription of the genes responsible for clearing cytosolic calcium (ATP2A2 and SLC8A $1^{18}$ ) increased over time, and the sequestration and extrusion of calcium became faster, enabling the hiPS-CMs to relax and respond to contractile triggers. Blocking $\mathrm{Ca}_{\mathrm{V}} 1.2$ with nifedipine or verapamil gradually reduced calcium transients in a training-dependent manner, while the response to caffeine indicated that only the early-stage intensity-trained tissues had functional intracellular calcium stores. Blocking SERCA with thapsigargin treatment to prevent SR/ER calcium uptake halted calcium transients, indicating that they are dependent on a functional sarcoplasmic reticulum. Subsequent addition of caffeine had no effect, consistent with calcium depletion of the SR/ER (Fig. 3b-d, Extended Data Fig. 9b-h).

Post-rest potentiation confirmed the functionality of SR/ER calcium stores in early-stage intensity-trained tissues. None of the other tested tissues responded to increased calcium levels or developed calcium alternans, owing to the lack of T-tubules and inefficient coupling between intracellular calcium entry and release. When CICR was blocked with ryanodine to test RYR2 function, only early-stage intensitytrained tissues showed a response, probably owing to the presence of T-tubules, which are necessary for CICR. Notably, the positive FFR was blunted by ryanodine treatment, and completely reversed when calcium sequestration by SERCA2a was blocked with thapsigargin, indicating the importance of both CICR and the reuptake of calcium into the sarcoplasmic reticulum (Fig. 3e, Extended Data Fig. 9i-k).

Because a functional $\beta$-adrenergic receptor system is dependent on both intracellular calcium reserves and the proximity of $\mathrm{Ca}_{V} 1.2$ channels and T-tubules ${ }^{4,26,27}$, comprehensive responses to $\beta$-adrenergic agonists are an indicator of phenotypic maturation ${ }^{28}$. We investigated whether early-stage intensity-trained tissues had an ionotropic response to isoproterenol, since this effect is not seen in current in vitro cardiac tissue models ${ }^{2,10}$. We detected positive chronotropic, ionotropic and lusitropic responses to isoproterenol in early-stage intensity-trained tissues, with $\mathrm{EC}_{50}$ (half-maximum effective concentration) values corresponding to those observed in clinical studies ${ }^{29}$ (Fig. 3f-h, Extended Data Fig. 10a, b).

Tissue maturity was necessary to recapitulate critical aspects of cardiac hypertrophy (HCM), a leading cause of sudden cardiac death in athletes ${ }^{2}$. As expected, hypertrophic tissues displayed decreased beating frequency and increased durations of intracellular calcium transients and decay times relative to healthy controls, and were not able to electromechanically capture when stimulated at high frequencies. The onset of HCM diminished the FDAR and resulted in a negative FFR, in

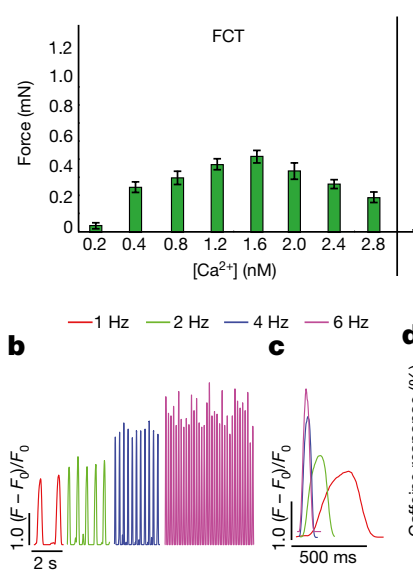

f

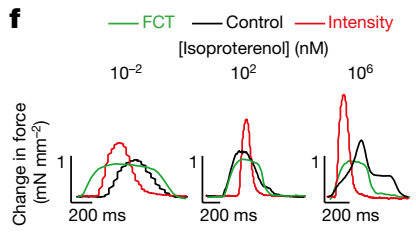

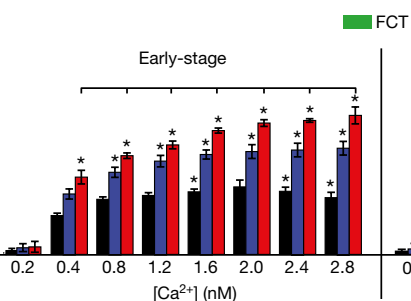

$\left[\mathrm{Ca}^{2+}\right](\mathrm{nM})$

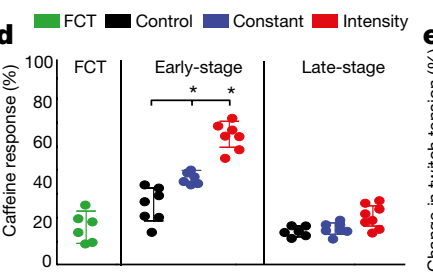

$$
\mathbf{g}
$$
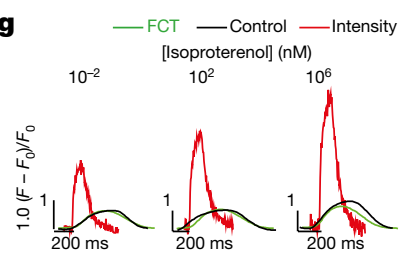

Control Constant Intensity

Late-stage Late-stage
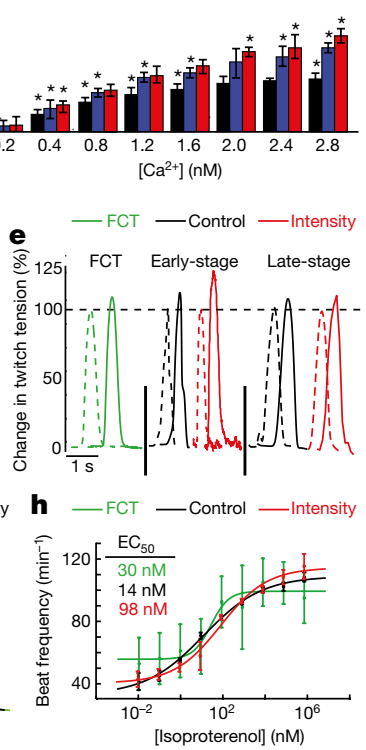

Fig. 3 | Mature calcium handling in earlystage intensity-trained tissues derived from C2A cells. a, Force of contraction during CICR. b, c, FDAR, shown by calcium traces. d, Calcium release after stimulation with $5 \mathrm{mM}$ caffeine. e, Force traces during post-rest potentiation with $10 \mathrm{~s}$ of rest. $\mathbf{f}-\mathbf{h}$, Ionotropic (f), lusitropic (g) and chronotropic (h) dosedependent responses. $\mathbf{i}, \mathbf{j}$, Cardiac tissue models of pathological hypertrophy (HCM) show decreased CICR over time (i) and reversal of positive FFR at higher pacing rates $(\mathbf{j})$. Data are for C2A cell line after four weeks of culture; mean $\pm 95 \%$ CI. Sample sizes are shown in Supplementary Information, 'Main figure data sample sizes'. $* P<0.05$ versus FCT using oneway ANOVA followed by Tukey's HSD test. In a and $\mathbf{d}$, line above graph indicates $P<0.05$ versus other training regimes using two-way ANOVA followed by Tukey's HSD test.
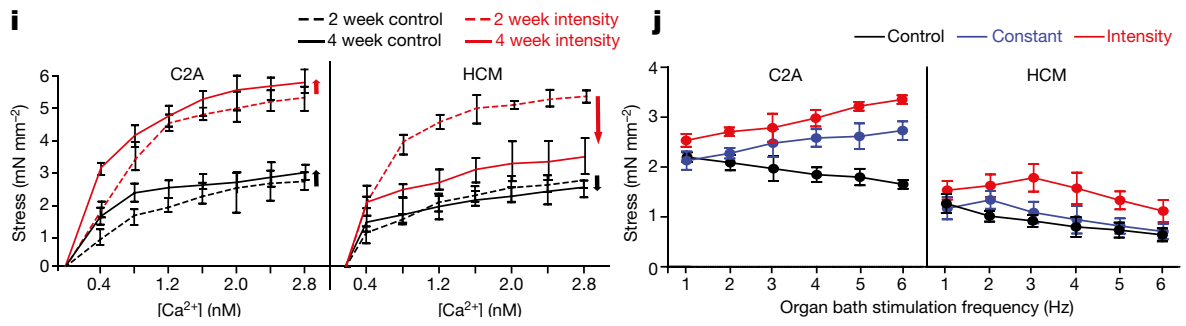
contrast to healthy tissues. Differences between healthy and diseased groups were most pronounced in the intensity-trained tissues (Fig. 3i, j, Extended Data Fig. 10c-f).

A recent study ${ }^{12}$ reported the culture of large $\left(7 \times 7 \mathrm{~mm}^{2}\right.$ to $\left.36 \times 36 \mathrm{~mm}^{2}\right)$ and thin $(50 \mu \mathrm{m})$ human heart tissues, grown without exogenous stimulation, that displayed less developed ultrastructure, no evidence of oxidative metabolism, slightly negative FFR, comparable APD and conduction velocity, and approximately fourfold higher generated force per unit cross-sectional tissue area when compared to the tissues cultured here. It would be instructive to explore how the different tissue geometries (very thin patches versus cylindrical muscle) and culture protocols (no external stimulation versus intensity training) ${ }^{12}$ contributed to the measured differences in structural and functional tissue outcomes in comparison to the present study.

In summary, we have demonstrated that adult-like human cardiac tissue can be grown from hiPS-CMs in fibrin hydrogel subjected to stretch and auxotonic contractions in just four weeks of in vitro culture. Two methodological advances underlie the accelerated cardiac maturation: the formation of tissues from early-stage hiPS-CMs, which displayed marked plasticity immediately after the initiation of spontaneous contractions; and physical conditioning with increasing intensity (mimicking mechanical loading during the fetal-postnatal transition). Under these conditions, tissues developed adult-like gene expression and tissue ultrastructure throughout the tissue volume, oxidative metabolism, FDAR, positive FFR and physiological calcium handling.

A notable result of our study is that highly accelerated and extensive maturation of molecular, structural and metabolic features of cardiac tissue was associated with slower and less complete establishment of mature cardiac function. We have demonstrated that physiological cell density is not sufficient to achieve adult-like mechanical function; that FDAR and positive FFR can be established at subnormal levels of force generation; and that T-tubules and oxidative metabolism are required for physiological FFR and calcium handling. Our tissue model does not recapitulate the macroscopic structure of the myocardium, and the maturation period of four weeks may be too short to establish all the functional features of adult myocardium. These factors may contribute to the contrast between the impressive morphological maturation and the less complete functional maturation. It would therefore be instructive to use this human cardiac tissue model to study the progression of functional maturation.

\section{Online content}

Any Methods, including any statements of data availability and Nature Research reporting summaries, along with any additional references and Source Data files, are available in the online version of the paper at https://doi.org/10.1038/s41586018-0016-3.

Received: 14 January 2016; Accepted: 27 February 2018. Published online 4 April 2018.

1. Bellin, M., Marchetto, M. C., Gage, F. H. \& Mummery, C. L. Induced pluripotent stem cells: the new patient? Nat. Rev. Mol. Cell Biol. 13, 713-726 (2012).

2. Matsa, E., Burridge, P. W. \& Wu, J. C. Human stem cells for modeling heart disease and for drug discovery. Sci. Transl. Med. 6, 239 (2014).

3. Wang, G. et al. Modeling the mitochondrial cardiomyopathy of Barth syndrome with induced pluripotent stem cell and heart-on-chip technologies. Nat. Med. 20, 616-623 (2014)

4. Yazawa, M. et al. Using induced pluripotent stem cells to investigate cardiac phenotypes in Timothy syndrome. Nature 471, 230-234 (2011).

5. Yang, X., Pabon, L. \& Murry, C. E. Engineering adolescence: maturation of human pluripotent stem cell-derived cardiomyocytes. Circ. Res. 114, 511-523 (2014).

6. Feric, N. T. \& Radisic, M. Maturing human pluripotent stem cell-derived cardiomyocytes in human engineered cardiac tissues. Adv. Drug Deliv. Rev. 96, 110-134 (2016).

7. Domian, I. J. et al. Generation of functional ventricular heart muscle from mouse ventricular progenitor cells. Science 326, 426-429 (2009).

8. Lundy, S. D., Zhu, W. Z., Regnier, M. \& Laflamme, M. A. Structural and functional maturation of cardiomyocytes derived from human pluripotent stem cells. Stem Cells Dev. 22, 1991-2002 (2013).

9. Nunes, S. S. et al. Biowire: a platform for maturation of human pluripotent stem cell-derived cardiomyocytes. Nat. Methods 10, 781-787 (2013)

10. Mannhardt, I. et al. Human engineered heart tissue: analysis of contractile force. Stem Cell Reports 7, 29-42 (2016)
11. Ribeiro, M. C. et al. Functional maturation of human pluripotent stem cell derived cardiomyocytes in vitro-correlation between contraction force and electrophysiology. Biomaterials 51, 138-150 (2015).

12. Shadrin, I. Y. et al. Cardiopatch platform enables maturation and scale-up of human pluripotent stem cell-derived engineered heart tissues. Nat. Commun. 8 1825 (2017).

13. Brette, F. \& Orchard, C. T-tubule function in mammalian cardiac myocytes. Circ. Res. 92, 1182-1192 (2003)

14. Wiegerinck, R. F. et al. Force frequency relationship of the human ventricle increases during early postnatal development. Pediatr. Res. 65, 414-419 (2009).

15. Lopaschuk, G. D. \& Jaswal, J. S. Energy metabolic phenotype of the cardiomyocyte during development, differentiation, and postnatal maturation. J. Cardiovasc. Pharmacol. 56, 130-140 (2010)

16. Jackman, C. P., Carlson, A. L. \& Bursac, N. Dynamic culture yields engineered myocardium with near-adult functional output. Biomaterials 111, 66-79 (2016).

17. Radisic, M. et al. Functional assembly of engineered myocardium by electrical stimulation of cardiac myocytes cultured on scaffolds. Proc. Natl Acad. Sci. USA 101, 18129-18134 (2004)

18. Eng, G. et al. Autonomous beating rate adaptation in human stem cell-derived cardiomyocytes. Nat. Commun. 7, 10312 (2016)

19. Hasenfuss, G. et al. Energetics of isometric force development in control and volume-overload human myocardium. Comparison with animal species. Circ. Res. 68, 836-846 (1991).

20. Chung, S. et al. Mitochondrial oxidative metabolism is required for the cardiac differentiation of stem cells. Nat. Clin. Pract. Cardiovasc. Med. 4, S60-S67 (2007).

21. Gong, G. et al. Parkin-mediated mitophagy directs perinatal cardiac metabolic maturation in mice. Science 350, aad2459 (2015).

22. Porter, G. A. Jr et al. Bioenergetics, mitochondria, and cardiac myocyte differentiation. Prog. Pediatr. Cardiol. 31, 75-81 (2011).

23. Vega, R. B., Horton, J. L. \& Kelly, D. P. Maintaining ancient organelles: mitochondrial biogenesis and maturation. Circ. Res. 116, 1820-1834 (2015).

24. Gottlieb, R. A. \& Bernstein, D. Metabolism. Mitochondria shape cardiac metabolism. Science 350, 1162-1163 (2015).

25. Sun, R., Bouchard, M. B. \& Hillman, E. M. C. SPLASSH: Open source software for camera-based high-speed, multispectral in-vivo optical image acquisition. Biomed. Opt. Express 1, 385-397 (2010).

26. Hong, T. et al. Cardiac BIN1 folds T-tubule membrane, controlling ion flux and limiting arrhythmia. Nat. Med. 20, 624-632 (2014).

27. Bers, D. M. Cardiac excitation-contraction coupling. Nature 415, 198-205 (2002).

28. Huebsch, $\mathrm{N}$ et al. Miniaturized iPS-cell-derived cardiac muscles for physiologically relevant drug response analyses. Sci. Rep. 6, 24726 (2016).

29. Tulloch, N. L. et al. Growth of engineered human myocardium with mechanical loading and vascular coculture. Circ. Res. 109,47-59 (2011).

Acknowledgements The authors acknowledge funding support from the National Institutes of Health of the USA (NIBIB and NCATS grant EB17103 (G.V.-N.); NIBIB, NCATS, NIAMS, NIDCR and NIEHS grant EB025765 (G.V.-N.); NHLBI grants HL076485 (G.V.-N.) and HL138486 (M.Y.); Columbia University MD/PhD program (S.P.M., T.C.); University of Minho MD/PhD program (D.T.); Japan Society for the Promotion of Science fellowship (K.M.); and Columbia University Stem Cell Initiative (D.S., L.S., M.Y.). We thank S. Duncan and B. Conklin for providing human iPSCs, M. B. Bouchard for assistance with image and video analysis, and L. Cohen-Gould for transmission electron microscopy services.

Reviewer information Nature thanks T. Kamp and the other anonymous reviewer(s) for their contribution to the peer review of this work.

Author contributions K.R.-B. and G.V.-N. designed the study. K.R.-B., K.Y. and G.V.-N. designed the tissue culture platform. K.R.-B., S.P.M., T.C. and D.T. cultured all tissue types with different stimulation conditions, and performed real-time and end-point assessments of tissue properties (including gene expression, histomorphology, ultrastructure, distributions of cardiac proteins, contractile behaviour and calcium handling). K.R.-B., S.P.M., T.C. and D.T. independently replicated the entire process of tissue cultivation and assessment. D.S. and L.S. expanded iPSCs and derived cardiomyocytes. K.R.-B. performed immunostaining for the presence of T-tubules. M.Y., K.M. and L.S. conducted single-cell dissociation and electrophysiology experiments. K.R.-B., S.P.M., T.C., M.Y. and G.V.-N. interpreted data and wrote the manuscript.

Competing interests G.V.-N. and K.R.-B. are co-founders of TARA Biosystems, a Columbia University spin-off that is commercializing the use of bioengineered human cardiac tissue for drug testing.

\section{Additional information}

Extended data is available for this paper at https://doi.org/10.1038/s41586018-0016-3

Supplementary information is available for this paper at https://doi.

org/10.1038/s41586-018-0016-3.

Reprints and permissions information is available at http://www.nature.com/ reprints.

Correspondence and requests for materials should be addressed to G.V.-N.

Publisher's note: Springer Nature remains neutral with regard to jurisdictional claims in published maps and institutional affiliations. 


\section{METHODS}

Cardiac differentiation of human iPSCs. Human induced pluripotent stem cells were obtained through material transfer agreements from S. Duncan, University of Wisconsin (C2A line), B. Conklin, Gladstone Institute (WT11 line) and M.Y., Columbia University (IMR90 line) and routinely checked for mycoplasma contamination. iPSCs were expanded on growth-factor-reduced Matrigel-coated plates (Corning) in mTeSR1 medium (Stemcell Technologies) that was changed on a daily basis, and passaged at $85-95 \%$ confluence in a 1:6 split using Accutase (Life Technologies). For the first $24 \mathrm{~h}$ after passaging, the culture medium was supplemented with $5 \mu \mathrm{M} \mathrm{Y-27632}$ dihydrochloride (Tocris, 1254).

Cardiac differentiation of iPSCs was initiated in confluent monolayers by replacing the mTeSR1medium with RPMI + B27-insulin medium, consisting of RPMI-1640 (Life Technologies), $1 \times$ B27 supplement without insulin (a source of omega- 3 fatty acids and the thyroid hormone that promotes cardiac maturation; Life Technologies), $100 \mathrm{U}$ penicillin (Life Technologies), $0.1 \mathrm{mg} / \mathrm{ml}$ streptomycin (Life Technologies) and $50 \mu \mathrm{g} / \mathrm{ml}$ ascorbic acid (Sigma, A4544). During the first $24 \mathrm{~h}$, the medium was further supplemented with activin A $(50 \mathrm{ng} / \mathrm{ml}, \mathrm{R} \& \mathrm{D}$ Systems) and bone morphogenetic protein 4 (BMP4, $25 \mathrm{ng} / \mathrm{ml}$, R\&D systems). From 24-72 h, the RPMI + B27-insulin medium was supplemented with vascular endothelial growth factor (VEGF, $10 \mathrm{ng} / \mathrm{ml}$, R\&D systems). Beyond $72 \mathrm{~h}$ through to the end of the differentiation process (up to 12 days), RPMI + B27 medium, consisting of RPMI-1640, $1 \times$ B27 supplemented with insulin (Life Technologies), $100 \mathrm{U}$ penicillin, $0.1 \mathrm{mg} / \mathrm{ml}$ streptomycin and $50 \mu \mathrm{g} / \mathrm{ml}$ ascorbic acid, was used and refreshed every two days. At day 12, the cells were characterized by flow cytometry using the cardiomyocyte-specific marker $\mathrm{cTnT}$ (clone 13-11, NeoMarkers). Differentiation typically resulted in cell populations containing $80-90 \% \mathrm{cTnT}^{+}$ cells at day 12 , which were subsequently used in experiments without selection for cardiomyocytes.

Human fetal cardiac tissues. Fetal hearts were purchased as surgical waste from Advanced Bioscience Resources (Alameda, CA), and delivered on ice within $2.5 \mathrm{~h}$ of surgery. Left ventricles were sectioned from the apex towards the atria into $7 \mathrm{~mm}$ long $\times 2 \mathrm{~mm}$ wide strips, washed three times in Hank's Balanced Salt Solution (Gibco), transferred to low attachment six-well plates (Nunc) containing RPMI + B27 medium, and placed into the incubator for $1 \mathrm{~h}$ before taking measurements. FCT strips were analysed in a similar manner to the cardiac tissues for contractile behaviour, force generation, gene expression, cardiac proteins, ultrastructure and histomorphology, as detailed below. In addition, RNA isolated from 32 pooled fetal hearts, from gestational weeks (GW)21-37, was obtained from Clontech (Mountain View, CA) for gene expression studies.

Human adult heart tissue. Adult heart cDNA (Clontech, 637213 and $3 \mathrm{H}$ Biomedical AB, SC6214) was used for measurement of gene expression. Tissue samples from adult left ventricles were obtained as surgical waste through an institutional review board at Columbia University.

Tissue bioreactor platform. The platform was assembled from two separate components: the wells for tissue culture, and an array of support structures with integrated elastomeric pillars for tissue attachment $(1 \mathrm{~mm}$ in diameter, $6 \mathrm{~mm}$ axisto-axis distance). Both components were fabricated out of polycarbonate using a computer numerical control $(\mathrm{CNC})$ milling machine with mating features for stability and repeatable positioning (Extended Data Fig. 1a-c).

The pillars were formed by centrifugal casting of polydimethylsiloxane (PDMS, Dow Corning Sylgard 184) through, and extending from, the polycarbonate support structures. The supports were first inserted into Delrin (polyoxymethylene) moulds fabricated by CNC machining and polydimethylsiloxane (PDMS; 10:1 ratio of base:curing agent) was centrifugally cast at 400 relative centrifugal force for $5 \mathrm{~min}$ and cured in an oven at $60^{\circ} \mathrm{C}$ for $1 \mathrm{~h}$. The resulting component consisted of three pairs of pillars to support the formation of three tissues (Extended Data Fig. 1d). Pillars were $1 \mathrm{~mm}$ in diameter, $9 \mathrm{~mm}$ in length, and spaced $6 \mathrm{~mm}$ axisto-axis.

The platform contained 12 wells for tissue culture that were patterned with exact 48-well-plate spacing, so that the platform corresponded to one quarter of the standard 48 -well plate. Each well had a bottom portion measuring $10 \mathrm{~mm} \times 4 \mathrm{~mm} \times 4 \mathrm{~mm}$ where the cells in hydrogel were introduced, and a wider top portion measuring $10 \mathrm{~mm} \times 7 \mathrm{~mm} \times 4 \mathrm{~mm}$ for culture medium. A glass slide was bonded to the bottom of the platform to enable microscopic observation.

Electrical stimulation of the cell-hydrogel tissues was performed using carbon rods (Ladd Research Industries) as electrodes. The carbon rods were placed into slots machined on each side of the culture well, aligned in parallel and positioned perpendicular to the long axis of both the culture well and the tissue. The electrodes were connected to a cardiac stimulator (Grass s88x) by platinum wires (Ladd Research Industries). Electrical stimulation was generated by a spatially uniform, pulsatile electrical field $(4.5 \mathrm{mV}$ intensity, $2 \mathrm{~ms}$ in duration, monophasic square waveform) perpendicular to the long axis of the tissue. The parameter settings amplitude, duration, frequency and waveform were controlled by the Grass s88x cardiac stimulator.
Culture of cardiac tissues. Differentiated hiPS-CMs were combined with supporting human dermal fibroblasts (Lonza), cultured in Dulbecco's Modified Eagle Medium (DMEM) supplemented with $10 \% \mathrm{v} / \mathrm{v}$ fetal bovine serum, $100 \mathrm{U}$ penicillin, and $0.1 \mathrm{mg} / \mathrm{ml}$ streptomycin, at a ratio of $75 \%$ hiPS-CMs and $25 \%$ fibroblasts. The cells were subsequently encapsulated in fibrin hydrogel by mixing $20 \mathrm{mg} / \mathrm{ml}$ human fibrinogen (Sigma), 100U/ml human thrombin (Sigma-Aldrich) and the cell suspension at a 3:1:1 ratio. The hydrogel solution (200 $\mu$ l containing 2 million cells) was dispensed into each well of the platform and allowed to polymerize at $37^{\circ} \mathrm{C}$ for $30 \mathrm{~min}$, so that the tissues readily formed around the pillars. Then, $800 \mu \mathrm{l}$ of RPMI + B27 medium containing $0.2 \mathrm{mg} / \mathrm{ml}$ aprotinin (Sigma-Aldrich, A3428) were added into each well, with an additional $30 \mathrm{ml}$ of RPMI + B27 medium containing $0.2 \mathrm{mg} / \mathrm{ml}$ aprotinin (Sigma-Aldrich, A3428) added to a 100-mm Petri dish (Corning, 430591) containing one platform (12 tissues). Subsequently, medium was changed every other day: $30 \mathrm{ml}$ RPMI $+\mathrm{B} 27$ medium containing $0.2 \mathrm{mg} / \mathrm{ml}$ aprotinin (Sigma-Aldrich, A3428) for the first seven days, and then $30 \mathrm{ml}$ $\mathrm{RPMI}+\mathrm{B} 27$ medium (either days 7-28 or days 7-84).

The pillars were designed to subject the tissues to mechanical loading, mimicking that in native human myocardium. Hydrogel compaction caused passive tension in the tissues as they were stretched between the two pillars, inducing elongation and alignment. Synchronous contractions induced by electrical stimulation generated dynamic forces in the contracting tissues attached to the pillars that were forced to work against the load.

Electrical stimulation was initiated on day seven, using one of three training regimes (Fig. 1a): control (no electrical stimulation, $0 \mathrm{~Hz}$ ), constant (constant frequency of $2 \mathrm{~Hz}$ ), and intensity training (a ramped stimulation that increased the frequency, from $2 \mathrm{~Hz}$ on day 7 to $6 \mathrm{~Hz}$ on day 21 , by $0.33 \mathrm{~Hz}$ per day; tissues were then stimulated at $2 \mathrm{~Hz}$ until day 28) (Extended Data Fig. 1e). Engineered tissues were randomly assigned to experimental groups. Tissues were cultured for a period of four weeks in 16 independent experiments, using three lines of iPSCs. Samples sizes for the main figures are shown in Supplementary Information, 'Main figure data sample sizes'.

Tissue properties were evaluated using real-time assessment of: amplitude and frequency of contractions, calcium handling, force generation, excitation threshold and maximum capture rate. End-point assays were performed to determine cell and tissue morphology (histologically), ultrastructure (by transmission electron microscopy), gene expression (using quantitative real-time PCR with reverse transcription (RT-PCR)) and the presence and distribution of cardiac proteins (immunohistochemistry).

Contractility analysis. Tissue contractility was measured by tracking the change in tissue area as a function of time. Live-cell, bright-field videos were acquired at rates of up to 150 frames per second using a Pike F-032b (Allied Vision Technologies) camera controlled with custom SPLASSH software ${ }^{25}$. Acquired video frames were inverted and an automated intensity threshold was used to identify cell location in the video frame. First, a baseline timepoint in the video corresponding to a relaxed tissue state was selected. Absolute differences in cell area from the baseline frame were then calculated to create a time course of cell area dynamics as a function of time. The resulting time courses were analysed using a native MATLAB automated peak finding algorithm to determine locations of maximum cell contraction indicated by the locations of local maxima in the timecourses. Beat period lengths were determined from the length of time between the pairs of local maxima. Beat frequencies were determined by inverting beat periods. Contraction amplitude relaxation times were measured from the length of time required for the tissue to relax from the peak contraction amplitude of the local maxima to the calculated relaxation amplitude (for example, the R90 time was the time elapsed between full contraction and $10 \%$ contraction).

Calcium handling. Tissues within culture platforms were loaded with Fluo-4 NW ( $50 \% \mathrm{v} / \mathrm{v}$, Life Technologies) in RPMI + B27 medium containing $5 \mu \mathrm{M}$ blebbistatin (Sigma) for $30 \mathrm{~min}$ at $37^{\circ} \mathrm{C}$ as necessary to reduce movement artefacts. Videos were acquired at a rate of 150 frames per second using a Pike F-032 camera (Allied Vision Technologies) as described in 'Contractility analysis'. Videos were analysed in MATLAB using a custom script that calculated the temporal changes in calcium fluorescence intensity. Specifically, each frame was normalized to a baseline background region chosen by the user to give baselinecorrected changes in minimum and maximum fluorescence values for each frame. The temporal change in fluorescence intensity was presented as a calcium transient trace from which the measurements were obtained. In brief, the calcium transient 'timing' was determined as the peak-to-peak values of two successive beats as defined by the peak maxima. Calcium transient 'amplitude' was determined by numerically integrating the area below the peak maxima relative to the baseline. Calcium transient traces were analysed during 5-mMcaffeine stimulation of tissues previously treated with either $1 \mathrm{mM}$ verapamil (Sigma-Aldrich) or $1 \mu \mathrm{M}$ thapsigargin (Sigma-Aldrich). Caffeine responses were quantified by comparing this calcium transient amplitude before and after the addition of $5 \mathrm{mM}$ caffeine (Sigma-Aldrich). 
Conduction velocity. A surrogate of conduction velocity was assessed by calcium propagation within the entire tissues that were pre-treated with $5 \mu \mathrm{M}$ blebbistatin (Sigma-Aldrich) to uncouple true $\mathrm{Ca}^{2+}$-dependent fluorescent motion from the fluorescent signals caused by motion artefacts. The conduction velocity was calculated by selecting two sections of the tissue within the region of calcium transient propagation and dividing the distance between the centres of these regions by the difference between their peak maxima.

Direct measurements of force. The force generation was measured directly, using an organ bath with high-sensitivity force transducers. Cardiac tissues and FCT strips were transferred to a commercial organ bath system (DMT Myograph) containing oxygenated modified Tyrode's solution ( $129 \mathrm{mM} \mathrm{NaCl}, 5 \mathrm{mM} \mathrm{KCl}, 2 \mathrm{mM}$ $\mathrm{CaCl}_{2}, 1 \mathrm{mM} \mathrm{MgCl}, 30 \mathrm{mM}$ glucose, $25 \mathrm{mM}$ HEPES, $\mathrm{pH}$ 7.4) supplemented with $2 \% \mathrm{~B} 27$ and maintained at a constant temperature of $37^{\circ} \mathrm{C}$ without electrical stimulation. All measurements were done using LabChart software (ADInstruments). The tissues were allowed to equilibrate for $15 \mathrm{~min}$ and any spontaneous beating measurements were recorded. The tissues were then allowed to equilibrate for another $15 \mathrm{~min}$ under electrical stimulation $(2 \mathrm{~Hz}, 5 \mathrm{~ms}, 80-100 \mathrm{~mA}$, rectangular pulses) in order to preload the tissues by manual stepwise adjustment of the tissue length to that of the maximal force generated, which assumes the optimal sarcomere length is thereby attained.

Twitch tension was measured by increasing the organ bath $\left[\mathrm{Ca}^{2+}\right]$ from 0.2 to $2.8 \mathrm{mmol} / \mathrm{l}$. Specifically, the extracellular calcium concentration was changed by changing the concentration of $\mathrm{CaCl}_{2}$ used in the Tyrode's solution. The tissues were subjected to electrical stimulation for $3 \mathrm{~min}$, and an average of 10 contractions were measured. The stimulation was then discontinued for 10,20 or $30 \mathrm{~s}$, and the tissues were allowed to recover for $2 \mathrm{~min}$. Post-rest potentiation measurements were subsequently obtained by analysing the change in twitch tension from the first beat upon re-initiation of electrical stimulation.

Contractility and twitch parameters were further investigated in response to the increasing electrical stimulation frequency within the organ bath as previously described ${ }^{25}$. Twitch forces were calculated as the average of the difference between cyclic peak maximum and minimum force and normalized to the cross-sectional area (obtained by measurement of tissue at the centre after force measurements). The force-frequency relationship was measured by increasing the electrical stimulation frequency from $1 \mathrm{~Hz}$ to $6 \mathrm{~Hz}$ in $1-\mathrm{Hz}$ increments. The tissues were subjected to each stimulation frequency for $30 \mathrm{~s}$ before increasing to the next stimulation frequency. The force data were measured at frequencies of $1-6 \mathrm{~Hz}$ (in $1 \mathrm{~Hz}$ increments) for all experimental groups (static, constant, early-stage and late-stage intensity-trained tissues, and human fetal tissue strips) and all iPSC lines.

Continuous recordings of force and calcium as a function of frequency. Continuous videos were recorded at a rate of 100 frames per second with a Zyla 4.2 sCMOS camera (Andor) to determine calcium transients and tissue displacement. The stimulation frequency was increased from $1 \mathrm{~Hz}$ to $6 \mathrm{~Hz}$ in $1-\mathrm{Hz}$ increments every $20 \mathrm{~s}$ (that is, every 2,000 frames). The calcium transients were analysed using custom MATLAB software as described above for measurements of calcium traces, and normalized to the baseline at each frequency as $\left(F-F_{0}\right) / F_{0}$. Tissue displacement was measured using the Spottracker module in ImageJ. The areas within the tissue were manually selected at baseline and tracked frame-to-frame to measure changes in the pixel displacement over time. Calcium dye loading was performed as previously described, but without the use of blebbistatin to block contractile motion. This enabled measurements of both calcium transient intensity and displacement during calcium imaging.

Immunofluorescent staining. For morphological analysis, tissues and FCTs were fixed by using gradually increasing concentrations of paraformaldehyde (1-4\%, in $1 \%$ increments, $1 \mathrm{~h}$ each). Whole tissues were paraffin-embedded and cut into 5 - $\mu \mathrm{m}$-thick sections. The sectioned tissues were quenched in $0.5 \mathrm{M} \mathrm{NH}_{4} \mathrm{Cl}$ for 30 min, permeabilized with $0.2 \%$ Triton X-100 in PBS for 15 min and then incubated in blocking solution ( $1 \%$ bovine serum albumin (BSA), $2 \%$ goat serum in PBS) for $2 \mathrm{~h}$. The following primary antibodies were incubated for $2 \mathrm{~h}$ in $1 \%$ BSA: anti-sarcomeric $\alpha$-actinin (1:200; Abcam ab9465), anti-cardiac troponin T (cTnT, 1:100; Thermo Scientific MS-295-P1), anti-ryanodine receptor 2 (RYR2, 1:100; Abcam ab2827), anti-Cav1.2 (1:200; Abcam ab58552), anti-BIN1 (1:100; Abcam ab137459), anti-mitochondria (1:50; Abcam ab3298) and anti-OXPHOS (1:100; Acris MS601-720). Actin was deteced with Alexa Fluor 350-phalloidin (Thermo Fisher A22281).

Tissues were washed three times for $5 \mathrm{~min}$ in $0.2 \%$ Triton X-100 and incubated with the corresponding secondary antibodies for $2 \mathrm{~h}$ : anti-mouse IgG-Alexa Fluor 488 (1:400; Invitrogen A21202), anti-rabbit IgG-Alexa Fluor 568 (1:400, Invitrogen, 81-6114) and anti-mouse IgG-Alexa Fluor 635 (1:400, Invitrogen, A31574). The tissues were washed and subsequently incubated with NucBlue (Molecular Probes, R37606) for nucleus counterstaining. The immunostained tissues were visualized using a confocal microscope (Olympus Fluoview FV1000).

For T-tubule immunostaining, tissues were incubated with WGA-Alexa Fluor 488 (Life Technologies, W11261) or di-8-ANEPPS (Life Technologies, D-3167) for
$20 \mathrm{~min}$ before permeabilization and subsequent staining with additional antibodies as described above.

Transmission electron microscopy. Tissues, FCTs, and adult heart tissue were fixed with $2.5 \%$ glutaraldehyde in $0.1 \mathrm{M}$ Sorenson's buffer $(\mathrm{pH} 7.2)$ for $1 \mathrm{~h}$ and sent to the Electron Microscopy and Histology (EM\&H Core) Facility at Weill Cornell Medical College for subsequent sample preparation, imaging and data interpretation in a blinded fashion. Samples were post-fixed for an additional hour with $1 \% \mathrm{OsO}_{4}$ in Sorenson's buffer. After dehydration, the samples were embedded, sectioned, stained with toluidine blue and examined under a JEM-1400 electron microscope.

Fraction of cells containing sarcomeres. Sectioned tissues were immunoflourescently labelled with sarcomeric $\alpha$-actinin and DAPI. Using the cell counter plugin in ImageJ, the DAPI-positive cells were marked and counted. Subsequently, all DAPI-positive cells that stained positive for $\alpha$-actinin were counted, and the percentage of cells containing sarcomeres of DAPI-positive cells was calculated.

Sarcomere length. Sarcomere length was determined in dissociated cells that were replated as a monolayer and stained with sarcomeric $\alpha$-actinin by measuring the distance between intensity peaks along the long axis of designated cell areas containing clear striations ${ }^{9}$. A minimum of three sarcomere lengths per cell were obtained in large numbers of cells from $n>6$ biological replicates.

Change in tissue area. The change in the projected tissue area (per cent change between the contracted and relaxed state) was experimentally determined in bright light by analysing the change tissues paced at $1 \mathrm{~Hz}$ and twice the excitation threshold, by custom-designed MATLAB code that used video edge-detection based on the contrast between the darker tissue and the lighter surrounding area. For each group and time point, the change in area was normalized to the change in area measured at day 6 , immediately before the application of electrical stimulation.

Cell morphology. Cells were enzymatically digested using serial digestions of collagenase type 1 and 2 (Worthington), and plated onto eight-well chamber slides (Laboratory-Tek, Sigma-Aldrich). The cells were allowed to attach for $72 \mathrm{~h}$ and imaged using phase-contrast microscopy. Cell area was quantified from the images using the '\%Area' function in ImageJ after thresholding of the cells in each image. Cell elongation ratio was calculated from these images using the 'Roundness' function in ImageJ, in which the aspect ratio was defined as (1 - Roundness), with 0 corresponding to a circle and 1 corresponding to a completely elongated object ${ }^{30}$. RT-PCR. Total RNA was purified from tissues according to the manufacturer's instructions using TRIzol (Life Technologies). For measurements of adult and FCT NPPA and NPPB expression, commercial tissues were used: adult heart, ages: 30-39, pooled from three male hearts (TaKaRa/Clontech Human RNA Master Panel II, 636643, lot no. 1208462 A); fetal hearts, GW: 21-37, pooled from 32 male and female fetal hearts (Clontech Human Fetal Heart Poly-A ${ }^{+}$RNA, 636156, lot no. 7110214; synthesized with oligo-dT20 and SSIII kit). Reverse transcription was performed using Ready-To-Go You-Prime First-Strand Beads (GE Healthcare, 27-9264-01) following the manufacturer's instructions. Gene expression was quantified by real-time PCR using SYBR Green primers (Life Technologies) in an Applied Biosystems Step One Plus. Data analysis was carried out using the $\log _{2}$-fold change normalized to late-stage week 1 tissue gene expression shown in Fig. 1b, Extended Data Fig. 2a. Data analysis was carried out using the fold change normalized to glyceraldehyde-3-phosphate dehydrogenase (GAPDH) gene expression in Extended Data Fig. 2b, 9c. Primers used are listed in Supplementary Information, 'Primer list'

Oxygen consumption rate and extracellular acidification rate. Engineered cardiac tissues were dissociated into single cells after four weeks of cultivation using activated papain solution containing $20 \mathrm{U} / \mathrm{ml}$ papain $\left(\sim 15 \mathrm{~min}\right.$ at $37^{\circ} \mathrm{C}$ with gentle tapping), as described for electrophysiological recordings. The enzyme reaction was terminated by adding $10 \%$ FBS in DMEM/F-12 culture medium. The dissociated hiPS-CMs were plated into XF96 Culture Plates (Seahorse Bioscience) coated with Matrigel (Corning, 354230) and cultured for three days. Subsequently, the plated hiPS-CMs were assayed in real-time using an XF-96 Extracellular Flux Analyzer (Seahorse Biosciences) for oxygen consumption rate (OCR) and extracellular acidification rate (ECAR) per the manufacturer's protocols.

Isoproterenol response. Isoproterenol was diluted in standard medium $(\mathrm{RPMI}+\mathrm{B} 27)$ to a concentration of $1 \mu \mathrm{M}$. Tissues were placed in the organ bath (as previously described) and equilibrated for $10 \mathrm{~min}$. Videos were captured, force measurements were recorded before and after addition of the drug, and the change in the generated force was determined.

Patch-clamp electrophysiology. Engineered cardiac tissues were dissociated into single cells for whole-cell patch-clamp recordings at four weeks using activated papain solution containing $20 \mathrm{U} / \mathrm{ml}$ papain from Caripa papaya (Sigma-Aldrich 76220), 1.1 mM EDTA, $67 \mu \mathrm{M}$ 2-mercaptoethanol (Sigma-Aldrich M3148), $5.5 \mathrm{mM}$ L-Cysteine-HCl (Sigma-Aldrich C7880) in $1 \times$ EBSS (Thermo Scientific/ Gibco 24010-043). This optimized protocol enabled healthy patchable single cardiomyocytes to be obtained without spontaneous beating from early-stage 
intensity-trained cardiac tissues. The same dissociation protocol using papain was also used for the other cardiac tissue samples. The tissues were incubated for $\sim 15 \mathrm{~min}$ at $37^{\circ} \mathrm{C}$ with gentle tapping, and the enzyme reaction was terminated by adding FBS (10\%) in DMEM/F-12 culture medium.

Whole-cell patch-clamp recordings of dissociated iPSC-CMs were conducted using a patch-clamp amplifier (MultiClamp 700B, Molecular Devices) and an inverted microscope equipped with differential interface optics (Nikon, Ti-U). Glass pipettes were prepared from borosilicate glass pipettes (Sutter Instrument BF150-110-10) and a micropipette puller (Sutter Instrument, Model P-97).

Current-clamp recording for action potential measurements was conducted in normal Tyrode's solution containing $140 \mathrm{mM} \mathrm{NaCl}, 5.4 \mathrm{mM} \mathrm{KCl}, 1 \mathrm{mM} \mathrm{MgCl}$, $10 \mathrm{mM}$ glucose, $1.8 \mathrm{mM} \mathrm{CaCl}_{2}$ and $10 \mathrm{mM}$ HEPES ( $\mathrm{pH} 7.4$ with $\mathrm{NaOH}$ at $25^{\circ} \mathrm{C}$ ) using the pipette solution $120 \mathrm{mMK}$ D-gluconate, $25 \mathrm{mM} \mathrm{KCl}, 4 \mathrm{mM} \mathrm{MgATP}, 2 \mathrm{mM}$ NaGTP, $4 \mathrm{mM} \mathrm{Na}_{2}$-phospho-creatine, $10 \mathrm{mM}$ EGTA, $1 \mathrm{mM} \mathrm{CaCl}_{2}$ and $10 \mathrm{mM}$ HEPES ( $\mathrm{pH} 7.4$ with $\mathrm{KCl}$ at $\left.25^{\circ} \mathrm{C}\right)$. Action potentials were stimulated $(5 \mathrm{~ms}, 0.3 \mathrm{nA})$ in a current clamp mode at $37^{\circ} \mathrm{C}(0.2 \mathrm{~Hz})$, recorded and analysed using Clampfit 10.4 (Axon Instruments)

Voltage-clamp measurements for $I_{\mathrm{K} 1}$ current recording were conducted using an extracellular solution containing $160 \mathrm{mM} \mathrm{NMDG}, 5.4 \mathrm{mM} \mathrm{KCl}, 2 \mathrm{mM} \mathrm{MgCl}$, $10 \mathrm{mM}$ glucose, $10 \mu \mathrm{M}$ nisoldipine, $1 \mu \mathrm{M} \mathrm{E}-4031$ and $10 \mathrm{mM}$ HEPES (pH 7.2 with $\mathrm{HCl}$ at $25^{\circ} \mathrm{C}$ ) and a pipette solution $150 \mathrm{mM} \mathrm{K}$-gluconate, $5 \mathrm{mM} \mathrm{EGTA}, 1 \mathrm{mM}$ $\mathrm{Mg}$-ATP and $10 \mathrm{mM}$ HEPES (pH 7.2 with $\mathrm{KOH}$ at $25^{\circ} \mathrm{C}$ ). The following pulse protocols were used: 2 -s voltage clamp applied from -130 to $+10 \mathrm{mV}$ (holding at $-40 \mathrm{mV}, 0.1 \mathrm{~Hz}, 2$-s voltage pulse). The $I_{\mathrm{K} 1}$ reversal potential $\left(\mathrm{Ba}^{2+}\right.$-sensitive current) had a negative slope conductance consistent with inward rectification, as previously described ${ }^{30}$. The current-voltage plot was analysed before and after the addition of $0.5 \mathrm{mM} \mathrm{BaCl}_{2}$ for $2 \mathrm{~min}$.

Dose-response curves. Drugs were diluted in standard medium (RPMI + B27). Successively higher doses of each drug were administered at concentrations of $10^{-11} \mathrm{M}$ to $10^{-5} \mathrm{M}$, in decigram increments. Videos were captured $\geq 5 \mathrm{~min}$ after each dose was administered, and processed using custom image processing software as described above. For chronotropic drugs, bright-field videos were taken at each drug concentration so that measurements of the beat frequency could be determined as a function of drug concentration. For ionotropic drugs, tissues were placed in the organ bath and force measurements were recorded as previously described at each drug concentration so that the measurements of the change in force generated could be determined as a function of drug concentration. Doseresponse curves for these parameters could be constructed by using MATLAB to fit the Hill equation for sigmoid curves to the data, to determine the corresponding $\mathrm{EC}_{50}$ value.
Paced isoproterenol response. Cardiac tissues were loaded with calcium dye as described above. Tissues were transferred to standard medium (RPMI + B27), paced at $1 \mathrm{~Hz}$ for $30 \mathrm{~min}$ to equilibrate, and the baseline video recordings were then obtained. Successively higher doses of isoproterenol were administered directly to the standard medium at concentrations of $0.01,100$ and $1,000,000 \mathrm{nM}$. Videos of tissues were captured $\geq 10 \mathrm{~min}$ after each dose was administered, and processed using custom-designed image analysis software as described above.

Cardiac hypertrophy model. Cardiac tissues were exposed to drugs known to induce pathological hypertrophy (angiotensin II, endothelin-1, isoproterenol) on day 6 following tissue formation. The first time point ( 1 week) was taken after $24 \mathrm{~h}$ of incubation with or without the drug. The majority of the HCM data shown are from pathologically induced HCM via endothelin-1 addition (unless data from all three drugs are shown), since the results were comparable amongst the three HCM-inducing agents.

Statistics and reproducibility. Data are shown as mean $\pm 95 \%$ CI. Differences between experimental groups were analysed by one-way or two-way ANOVA. Post hoc pairwise analysis was done using Tukey's HSD test. Electrophysiological data were analysed by one-way ANOVA Barlette's test with multiple comparisons. $P$ values $<0.05$ were considered significant for all statistical tests. The reproducibility of the data are demonstrated by the number of independent biological samples. The number of independent experiments performed for each dataset reported in the main figures is detailed in Supplementary Information, 'Main figure data sample sizes'. Details of the sample sizes used in the Extended Data are included in the respective figure legends.

Reporting Summary. Further information on experimental design is available in the Nature Research Reporting Summary linked to this paper.

Code availability. The study used a combination of commercial and open-source software packages, which are specified in the Methods, and custom-designed software that will be made available to interested investigators upon reasonable request. Data availability. Source data for quantitative data shown in all figure panels are available without restrictions and can be accessed at https://doi.org/10.6084/ $\mathrm{m} 9$.figshare.5765559. The detailed experimental protocol is available from Protocol Exchange $^{31}$.

30. Ma, J. et al. High purity human-induced pluripotent stem cell-derived cardiomyocytes: electrophysiological properties of action potentials and ionic currents. Am. J. Physiol. Heart Circ. Physiol. 301, H2006-H2017 (2011).

31. Morikawa, K., Song, L., Ronaldson-Bouchard, K., Vunjak-Novakovic, G. \& Yazawa, M. Electrophysiological recordings of cardiomyocytes isolated from engineered human cardiac tissues derived from pluripotent stem cells. Protoc. Exch. https://doi.org/10.1038/protex.2018.030 (2018). 

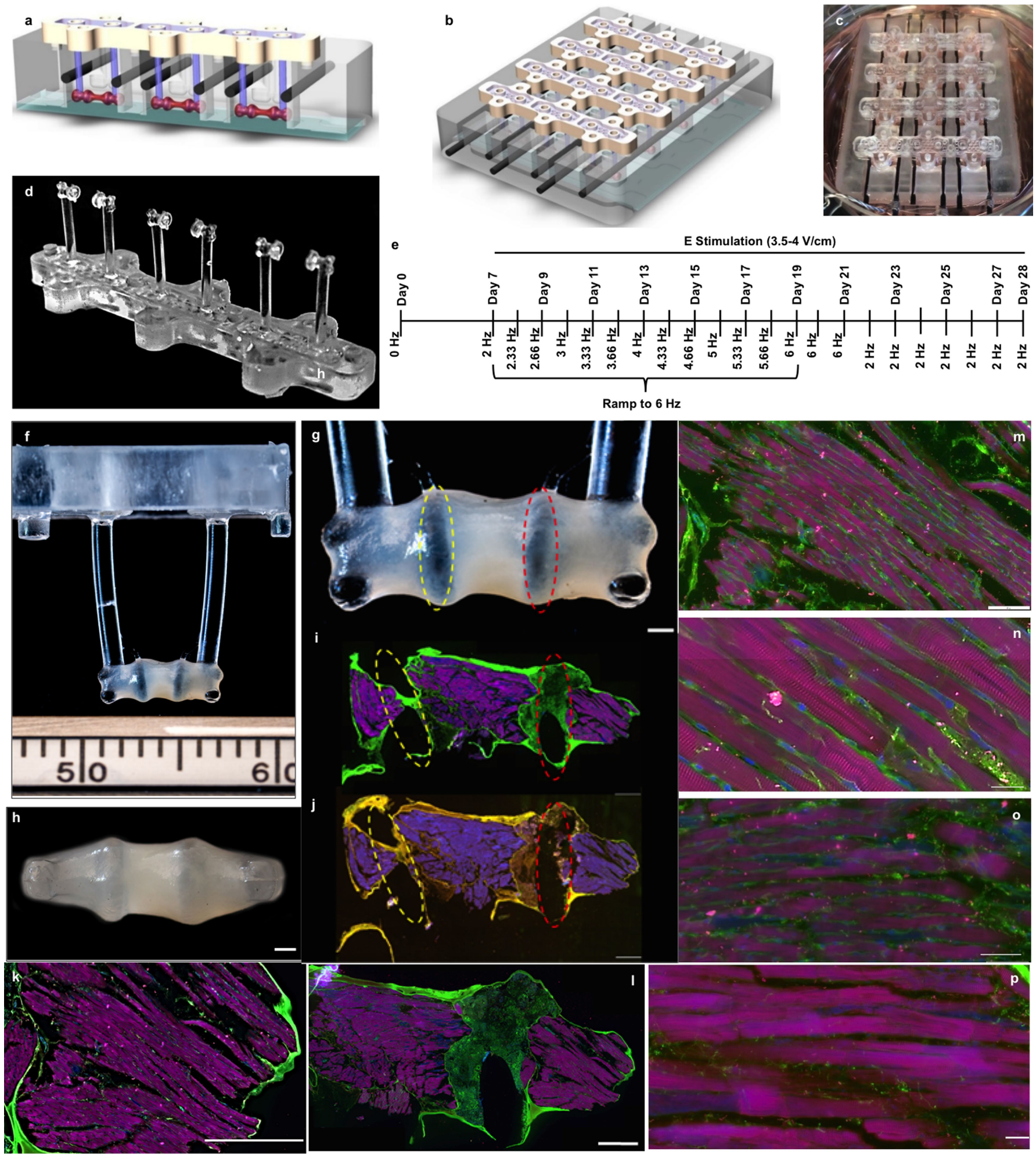

Extended Data Fig. 1 | Experimental design and overall appearance of cardiac tissues. a, Schematic of the pillars (purple) placed via interlocking mating components between the bioreactor wells (grey) and pillar lid (yellow) with tissues (pink) formed around the pillars, and electrodes (black) placed perpendicular to the cardiac tissues. A glass slide (blue) is epoxied to the bottom of the bioreactor to enable image acquisition. b, A schematic of the assembled bioreactor. c, Photographs of the cardiac tissues cultured within the bioreactor. d, The tissue pillar. e, Increase in the electrical stimulation frequency throughout the intensity training regime. $\mathbf{f}-\mathbf{h}$, Photographs of the tissues attached to pillars at the end of four-week cultivation: side view (f, $\mathbf{g})$, bottom view (h). Scale bars, $500 \mu \mathrm{m}$. i, j, Immunofluorescence in serial sections of the early-stage intensity-trained tissue. The dotted yellow and red lines in $\mathbf{g}, \mathbf{i}, \mathbf{j}$ indicate corresponding pillar placement within the tissue. Scale bars, $500 \mu \mathrm{m}$. $\mathbf{k}-\mathbf{p}$, Immunofluorescence in serial sections of the early-stage intensitytrained tissue in i. WGA, green; $\alpha$-actinin, pink; nuclei, blue. Scale bars, $\mathbf{i}-\mathbf{l}, 500 \mu \mathrm{m} ; \mathbf{m}, 100 \mu \mathrm{m} ; \mathbf{n}, 20 \mu \mathrm{m} ; \mathbf{o}, \mathbf{p}, 50 \mu \mathrm{m}$. Images were selected to include landmark features that facilitate localization and comparisons. Similar results were obtained from three independent experiments. 
a
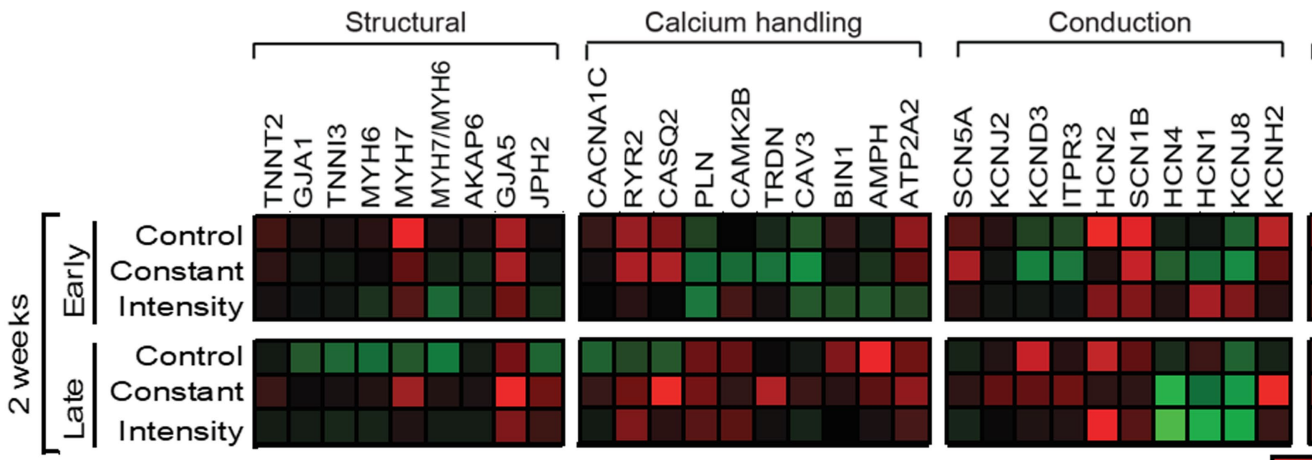
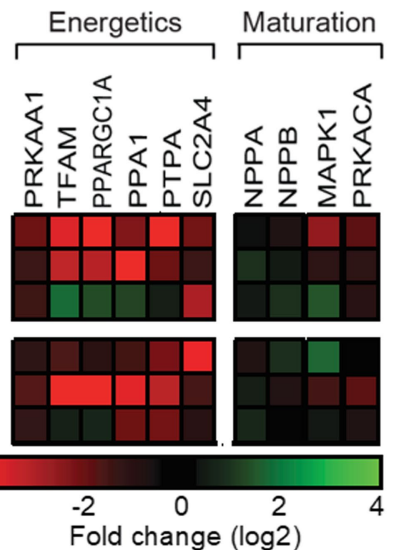

b
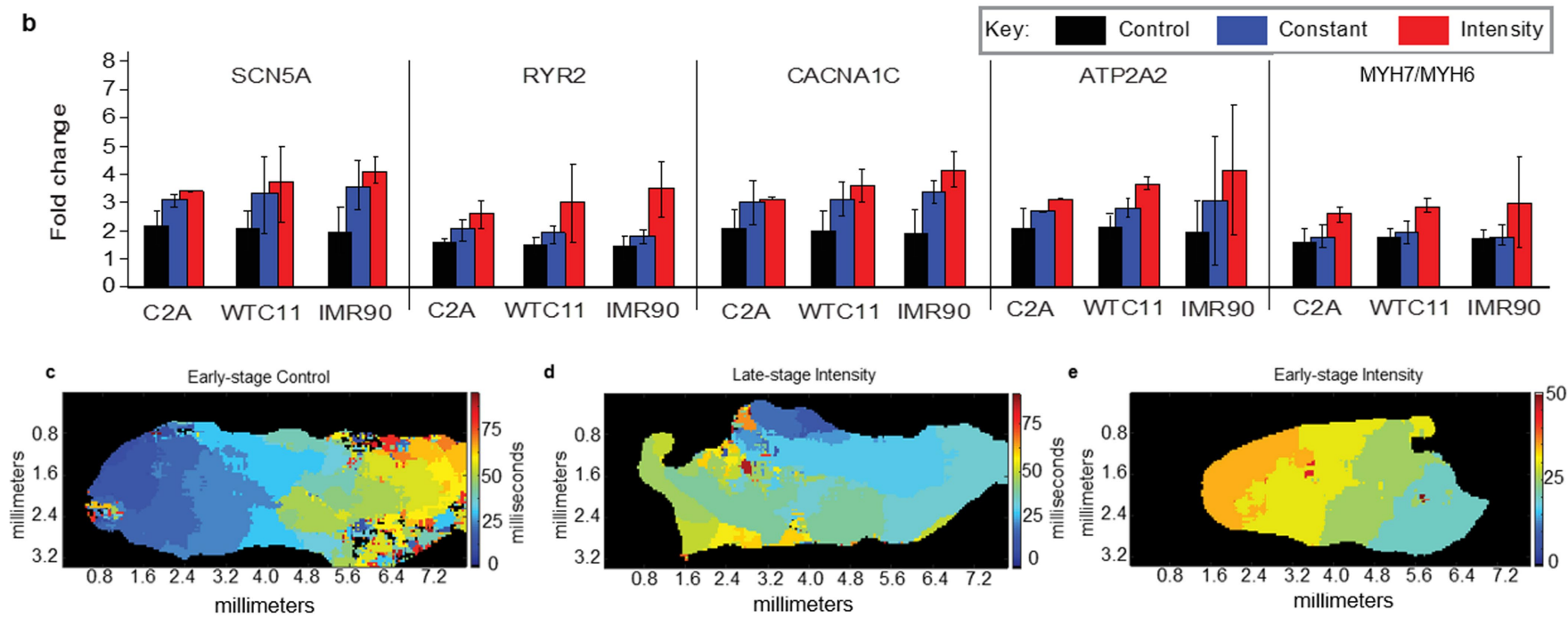

d
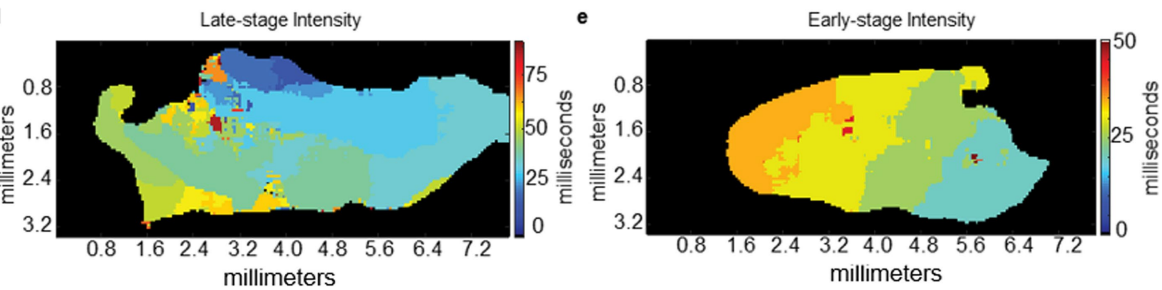

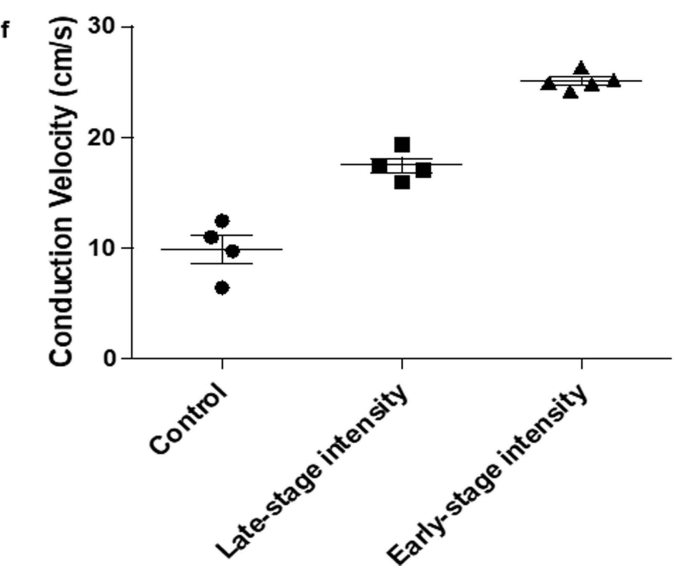

Extended Data Fig. 2 | Enhanced gene expression and conduction in intensity-trained cardiac tissues over time. a, Quantitative gene expression in FCTs and C2A iPSC cardiac tissues after two weeks of culture, as determined by RT-PCR; shown as fold change relative to late-stage tissues at the start of stimulation. b, Quantitative gene expression in early-stage cardiac tissues, normalized to GAPDH, from three different iPSC lines as determined by RT-PCR after four weeks of culture. $n=12$ biologically independent samples per group; mean $\pm 95 \%$ CI; no significant difference between the cell lines by two-way ANOVA. c-f, Representative conduction velocity activation maps for early-stage
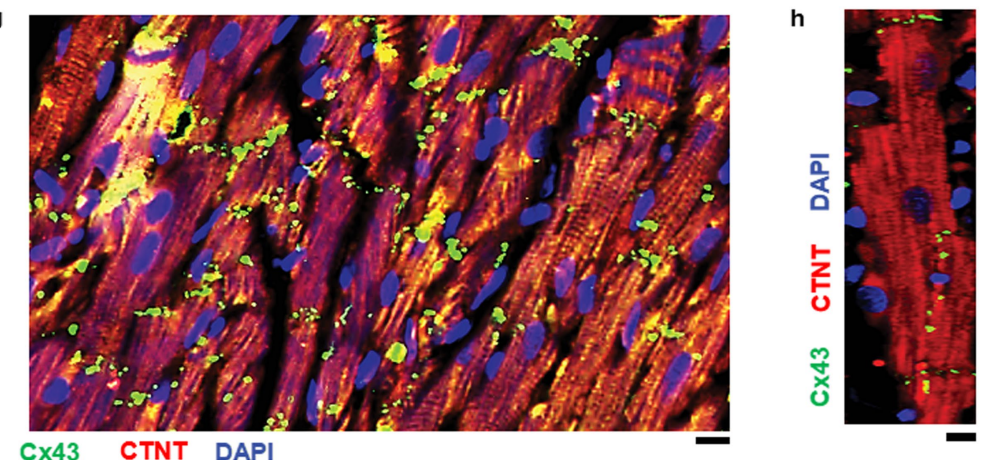

control (c), late-stage intensity-trained (d) and early-stage intensitytrained (e) cardiac tissues, and surrogate of conduction velocity in earlystage and late-stage C2A iPSC cardiac tissues after four weeks of culture, assessed by calcium propagation (f). Mean \pm s.e.m., $n=4-5$ biologically independent samples per group. $\mathbf{g}$, h, Representative immunofluorescence of gap junction (connexin-43 (Cx43), green) expression in early-stage intensity-trained iPSC cardiac tissue after four weeks of culture, at low (g; scale bar, $10 \mu \mathrm{m})$ and high magnification (h; scale bar, $5 \mu \mathrm{m})$. cTnT, red; nuclei (DAPI), blue. Similar results were obtained from four independent experiments. 
early control $(n=9)$

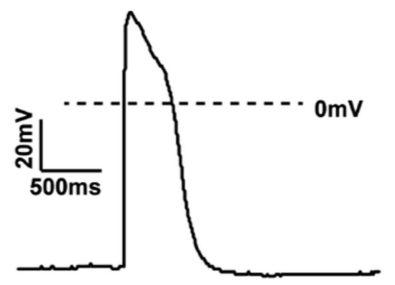

late intensity $(n=9)$

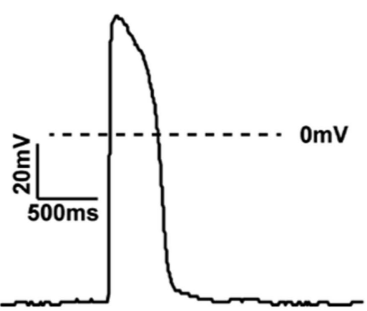

early intensity $(n=14)$
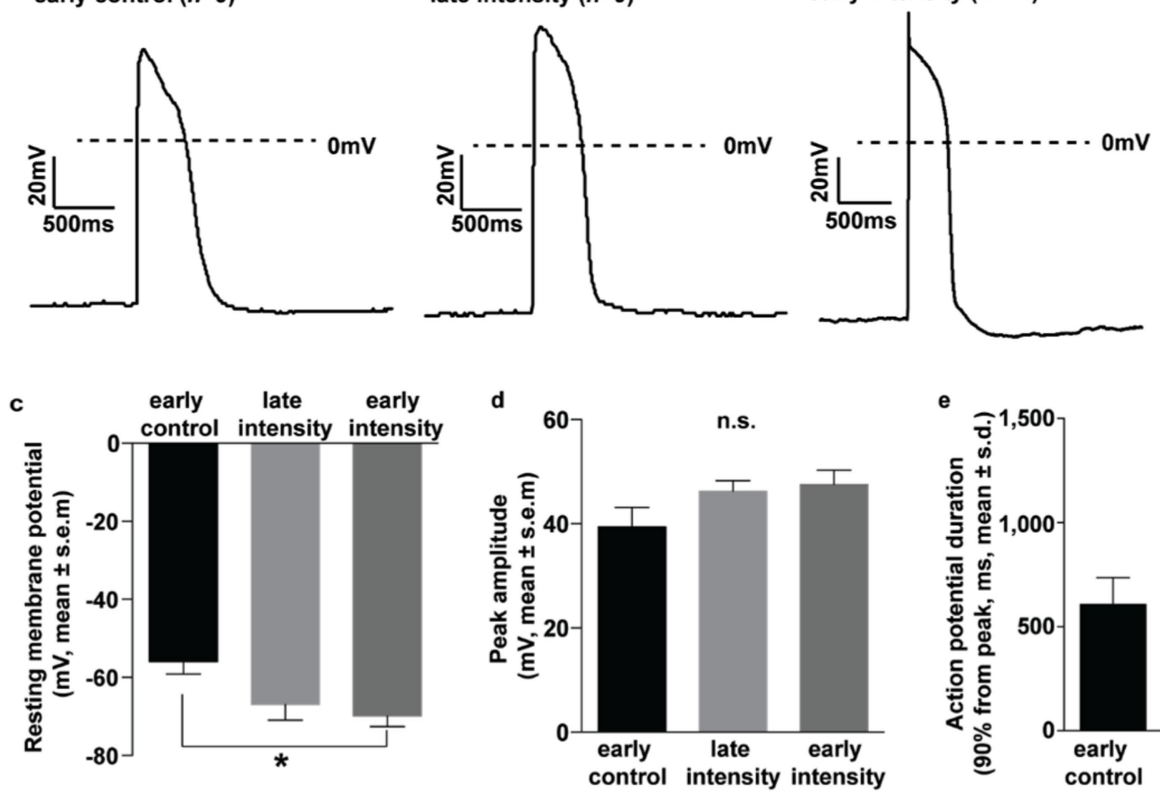

g

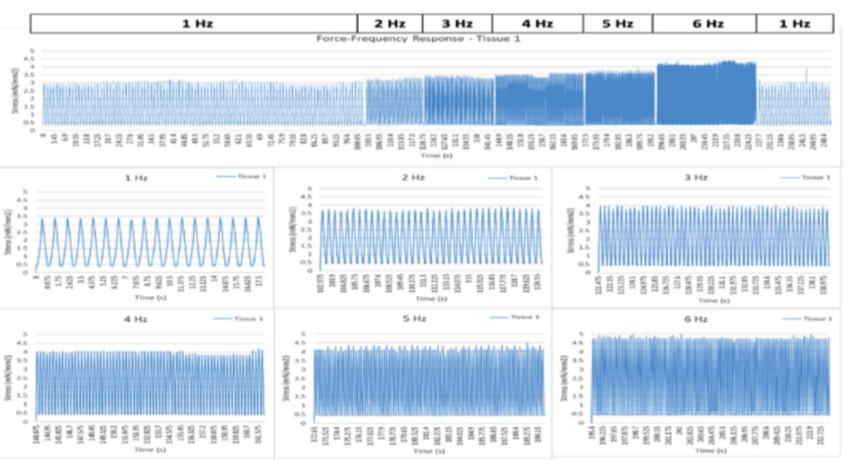

i

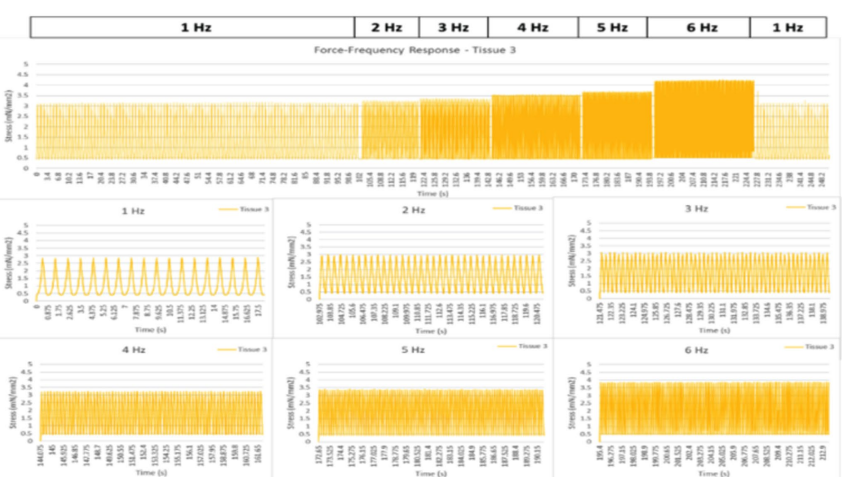

Extended Data Fig. 3 | Electrophysiological characterization of human engineered cardiomyocytes. a, Representative traces of action potentials in early-stage control $(n=9)$, late-stage intensity-trained $(n=9)$ and early-stage intensity-trained $(n=14)$ groups. $n$ is the number of biologically independent samples obtained during two independent experiments. b, Representative traces of $I_{\mathrm{K} 1}$ current for the early-stage intensity-trained group using voltage-clamp mode. c-f, Electrophysiology data after four weeks of culture showing the resting membrane potential (c), peak amplitude (d), duration of action potential (e) and upstroke velocity (f) obtained in two independent experiments, resulting in biologically
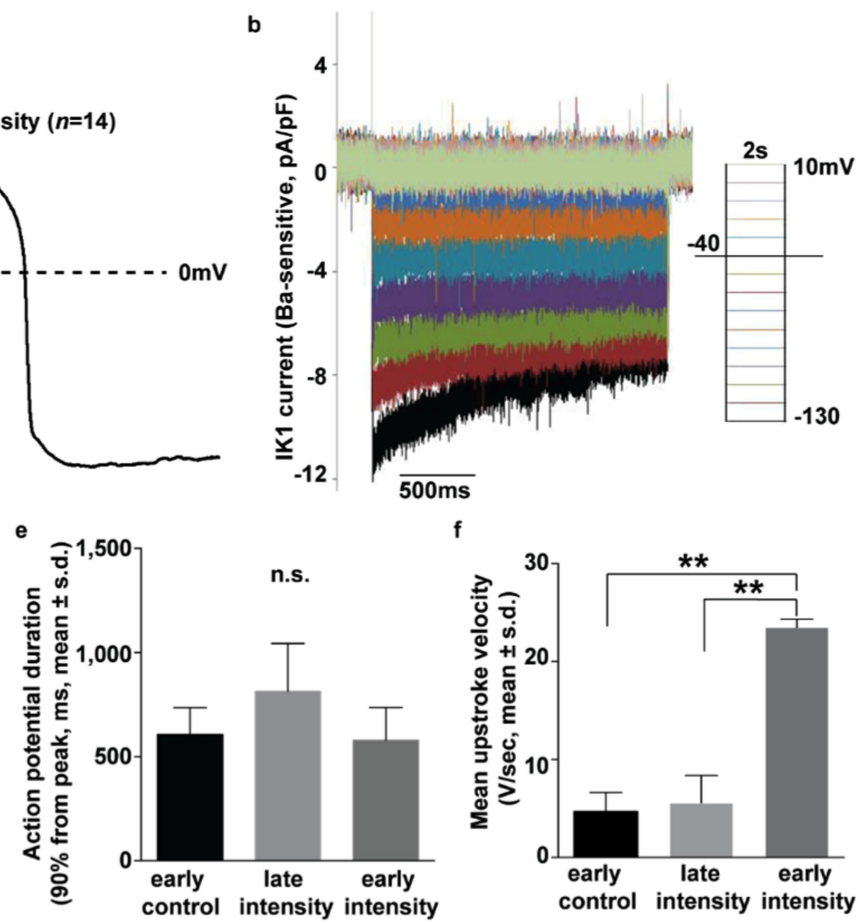

h
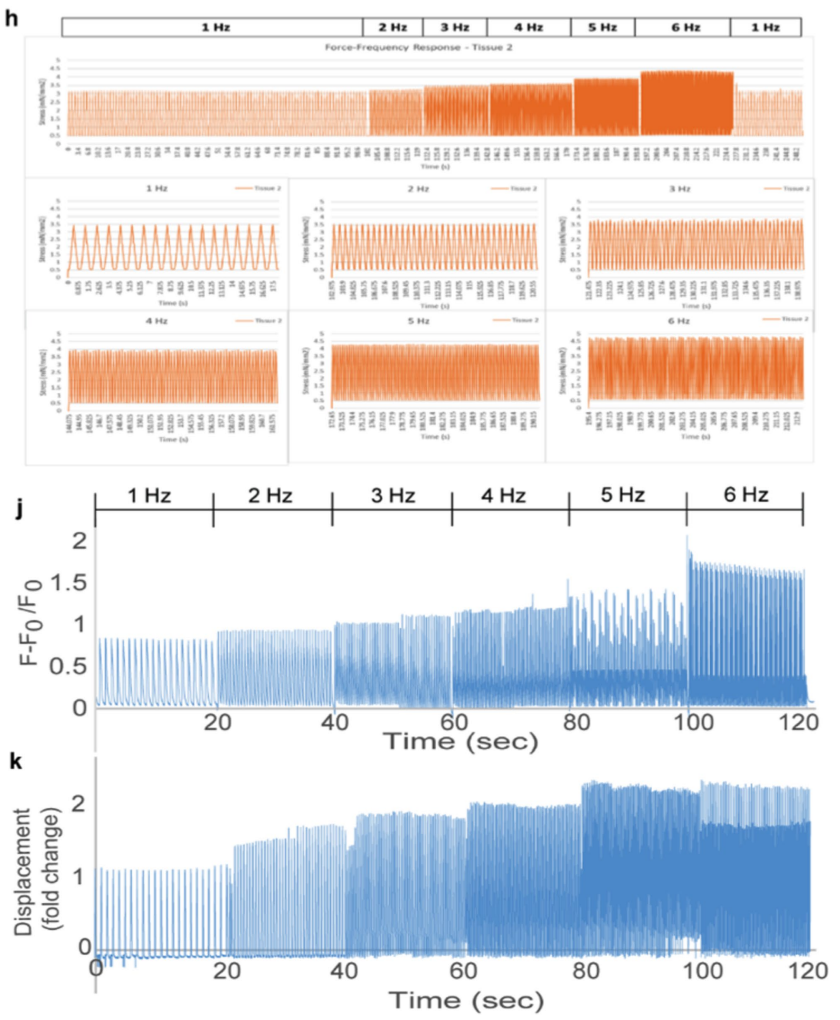

independent data from early-stage control $(n=9)$, late-stage intensitytrained $(n=9)$ and early-stage intensity-trained $(n=14)$ groups.

$* * P<0.01, * P<0.05$ using one-way ANOVA Bartlett's test with multiple comparison. n.s., not significant. g-i, Representative continuous organ bath force recordings under electrical pacing from $1-6 \mathrm{~Hz}$ from three biologically independent early-stage intensity trained tissues (C2A cells) from one experiment. $\mathbf{j}, \mathbf{k}$, Representative continuous recordings from an early-stage intensity-trained tissue (C2A cells) under electrical pacing from $1-6 \mathrm{~Hz}$ of calcium $(\mathbf{j})$ and surrogate force $(\mathbf{k})$ as determined by tissue displacement, normalized to $1 \mathrm{~Hz}$. 
a

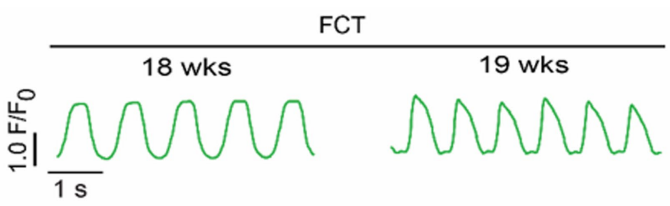

b

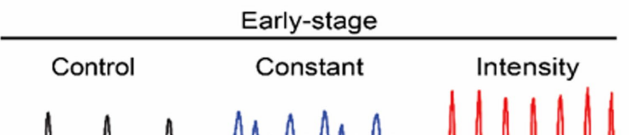

2 wks

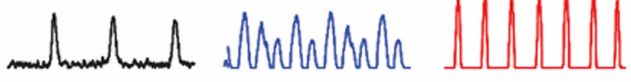

3 wks

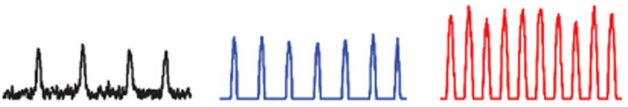

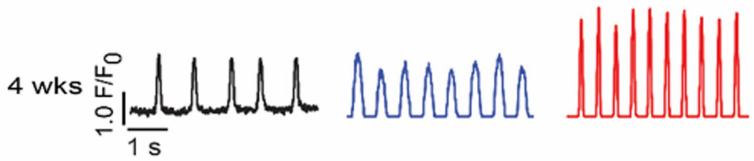

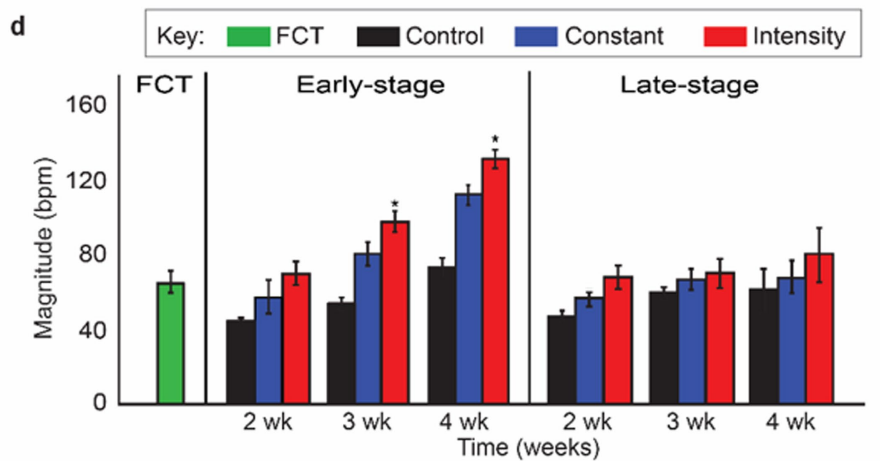

Key: — FCT Control — Constant —ntensity

c

\begin{tabular}{lcl}
\multicolumn{3}{c}{ Late-stage } \\
\hline Control $\quad$ Constant
\end{tabular}

2 wks

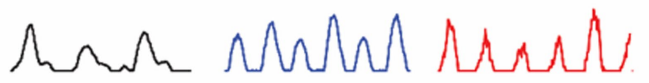

3 wks

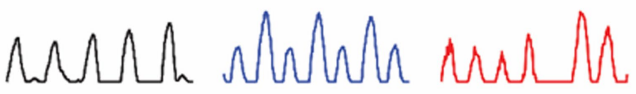

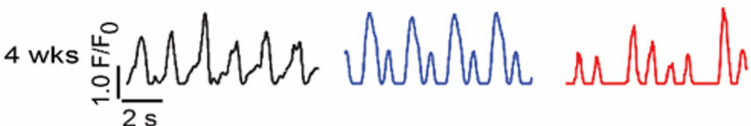
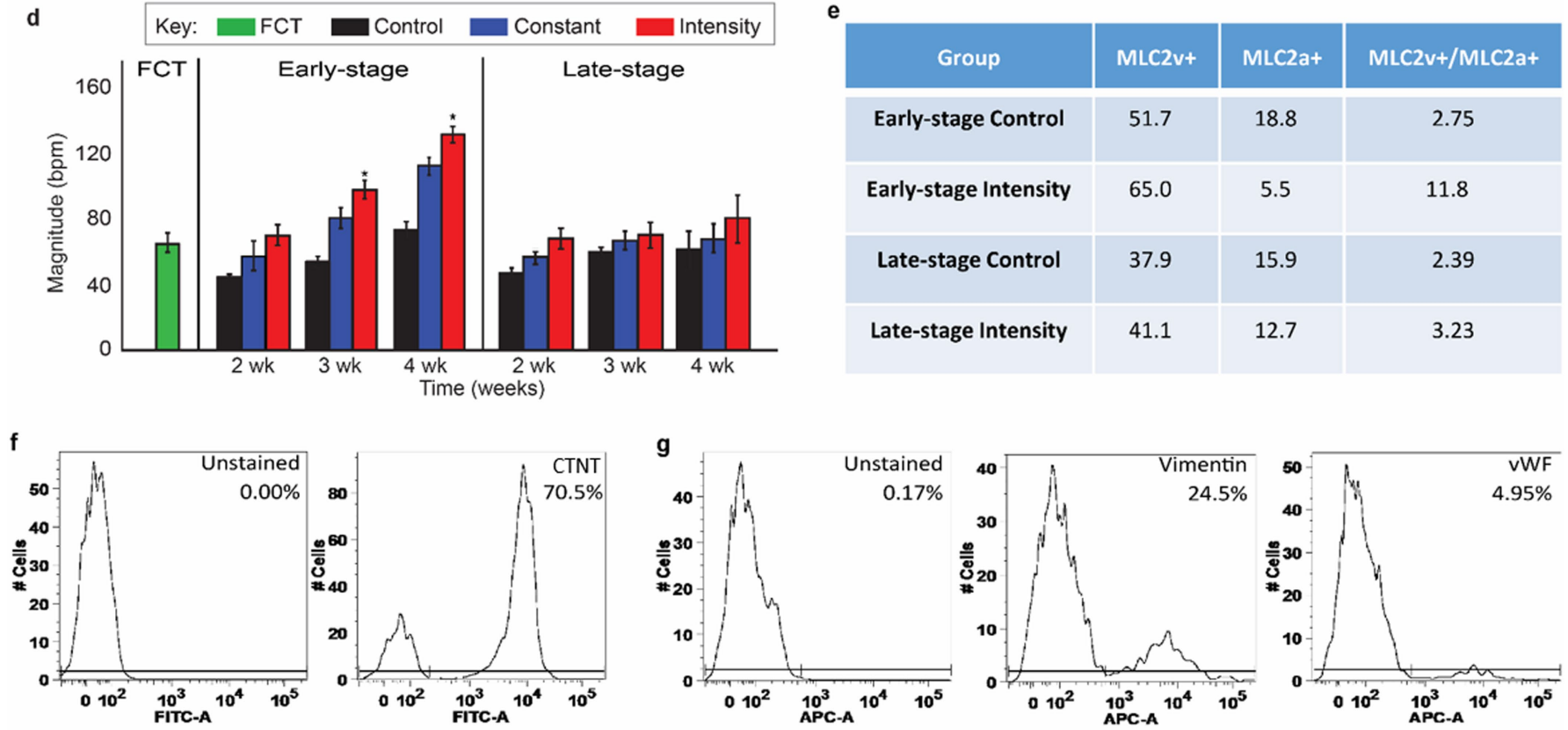

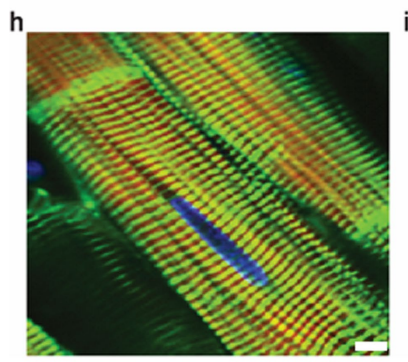

a-actinin, CTNT, DAPI

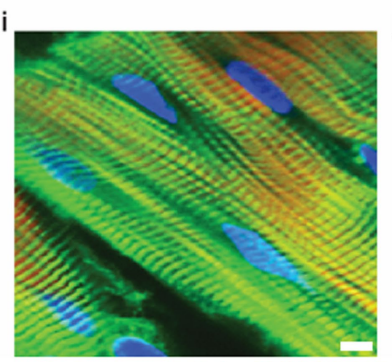

$\alpha$-actinin, CTNT, DAPI
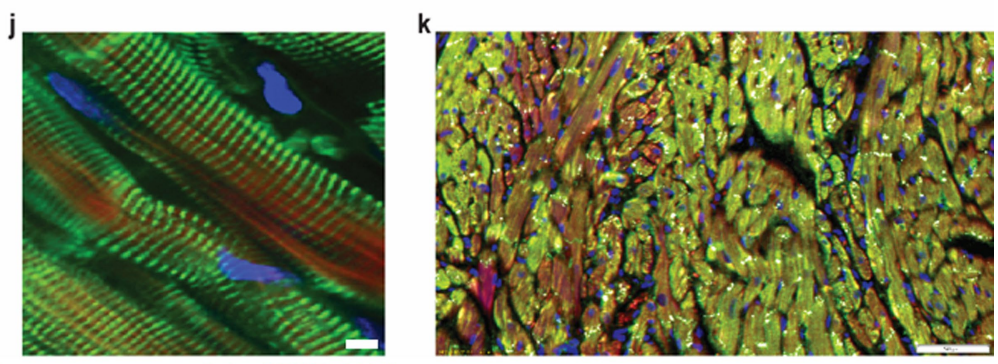

a-actinin, CTNT, DAPI

line) by FACS analysis after four weeks of culture: cardiac cells (f; c $\mathrm{CnT}$ ), and supporting fibroblast cells and endothelial cells (g; vimentin and von Willebrand Factor(vWF), respectively). $\mathbf{h}-\mathbf{j}$, Representative immunofluorescence of whole tissues showing the enhanced cardiac ultrastructure ( $\alpha$-actinin, green; cTnT, red; nuclei, blue) in early-stage cardiac tissues from the C2A line (h), WTC11 cell line (i), and IMR90 cell line (j) after four weeks of culture. Scale bars, $5 \mu \mathrm{m}$; experiment repeated independently 14 times with similar results. $\mathbf{k}$, Representative immunofluorescence showing the cell population in a histological section from early-stage cardiac tissue (C2A line) after four weeks of culture. cTnT, green; vimentin, red; nuclei, blue. Scale bar, $50 \mu \mathrm{m}$; experiment repeated independently two times with similar results. population within cardiac tissues (C2A line) after four weeks of culture by fluorescence-activated cell sorting (FACS) analysis. $\mathbf{f}, \mathbf{g}$, Characterization of cells isolated from early-stage intensity-trained cardiac tissues (C2A 

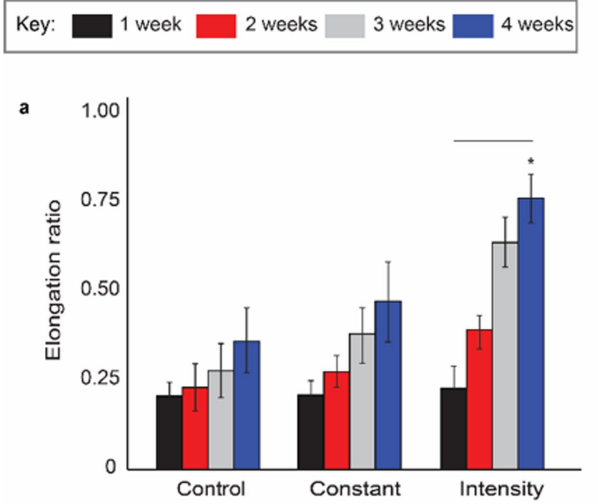

b
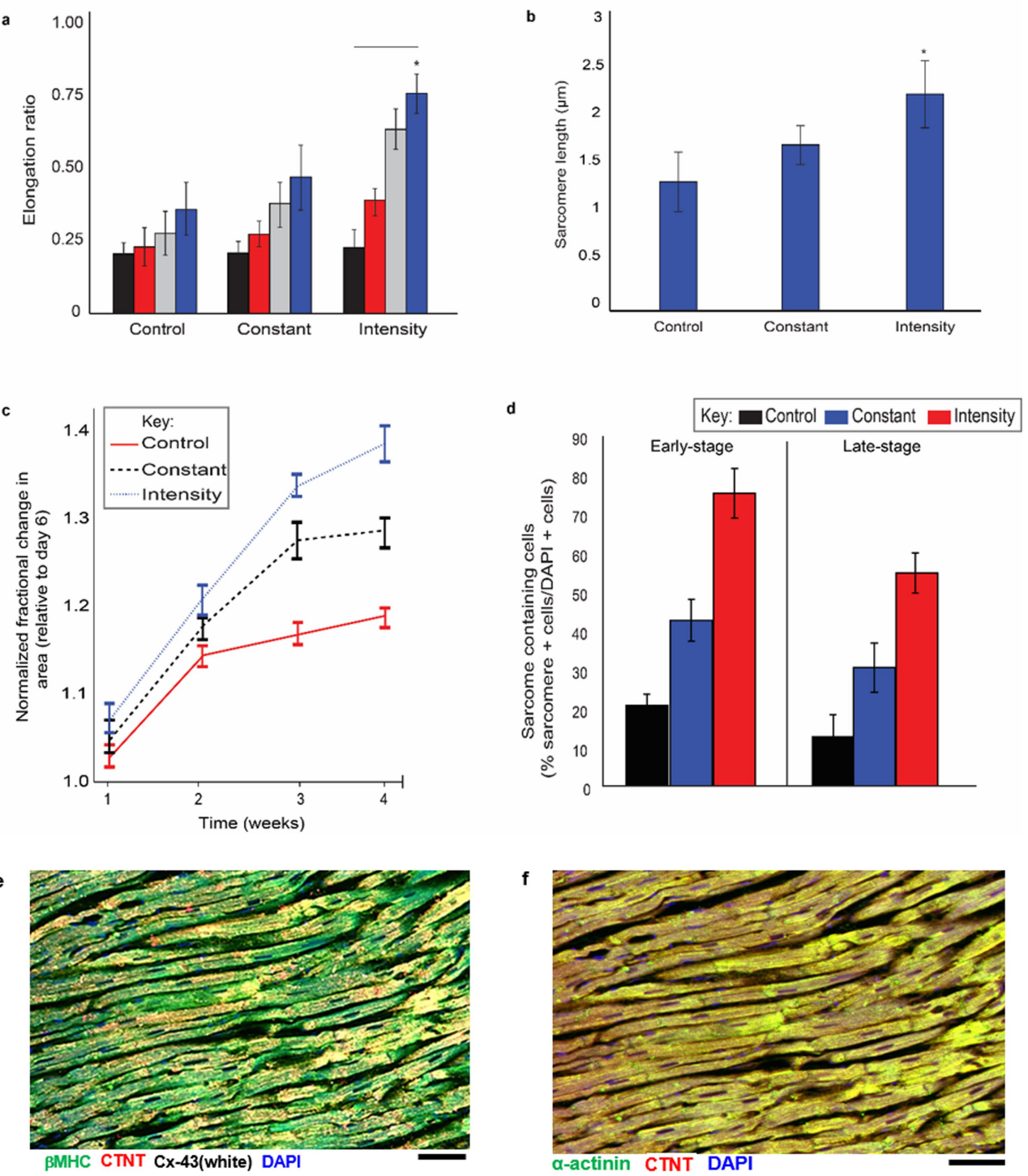

f

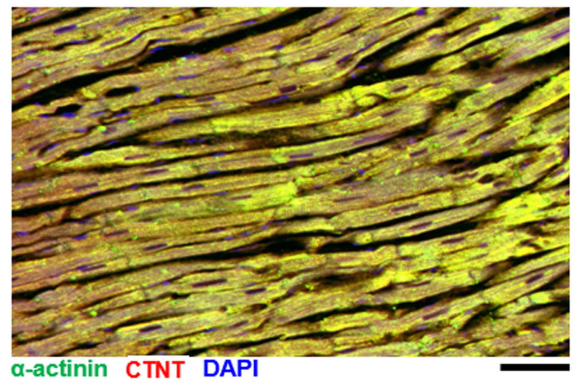

$\alpha$-actinin CTNT DAPI
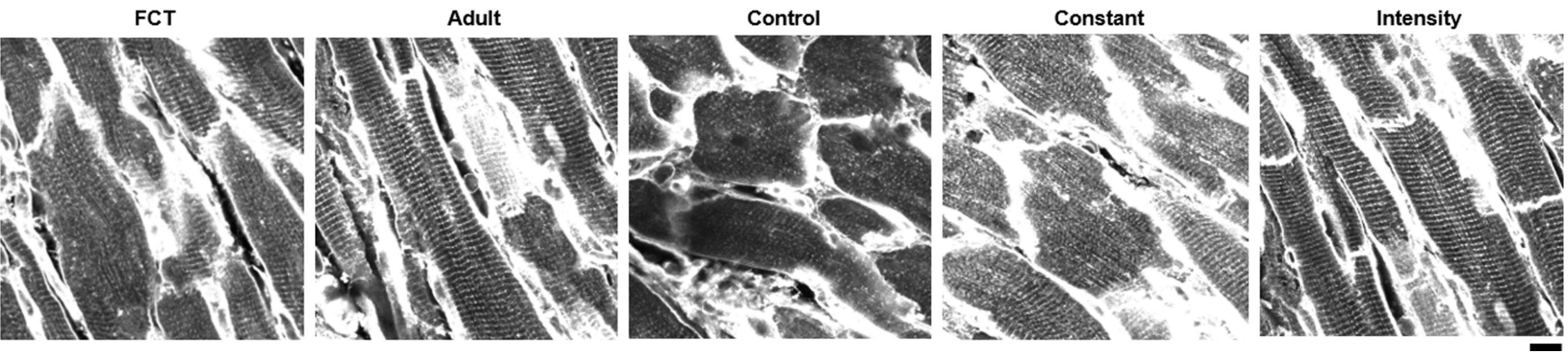

Extended Data Fig. 5 | Physiological hypertrophy within cardiac tissues enhances contractility. a-c, Physiological hypertrophy of cardiomyocytes cultured in the electromechanically conditioned cardiac tissue format increases as a function of time and training regime beyond FCT levels, as shown by cell elongation ratio (a) and sarcomere length (b). $n=326$ biological replicates from 15 independent samples in one experiment. c, This enables the change in area while being electrically paced at $1 \mathrm{~Hz}$, an indirect measure of fractional shortening, to similarly increase beyond FCT levels as a function of time and training regime. Data represent the ratio of the change in area for a given time point and the change in area at day 6. $n=6$ biologically independent samples per group; mean $\pm 95 \% \mathrm{CI}$; $* P<0.05$ compared to FCT group at week four by ANOVA with Tukey's HSD test; line above graph indicates $P<0.05$ compared to other training regimes by two-way ANOVA with Tukey's HSD test. d, The enhanced cardiac ultrastructure in intensity-trained early-stage cardiac tissues is documented by the quantification of sarcomere distribution in cardiac tissues. $n=12$ biologically independent samples per group, mean $\pm 95 \%$ CI. e, f, Representative immunofluorescence of gap junction (connexin- 43 $(\mathrm{Cx} 43)$, white) in early-stage iPSC cardiac tissue ( $\beta$-myosin heavy chain ( $\beta$-MHC), green; cTnT, red; nuclei (DAPI), blue) (e) and cardiac ultrastructure in early-stage iPSC cardiac tissue ( $\alpha$-actinin, green; $c$ TnT, red; nuclei (DAPI), blue) (f) after four weeks of culture. Scale bar, $50 \mu \mathrm{m}$; experiment repeated independently three times with similar results. g, $\alpha$-Actinin immunofluorescence (white) in cardiac tissues after four weeks of culture. Scale bar, $10 \mu \mathrm{m}$; experiment repeated independently two times with similar results. 
a
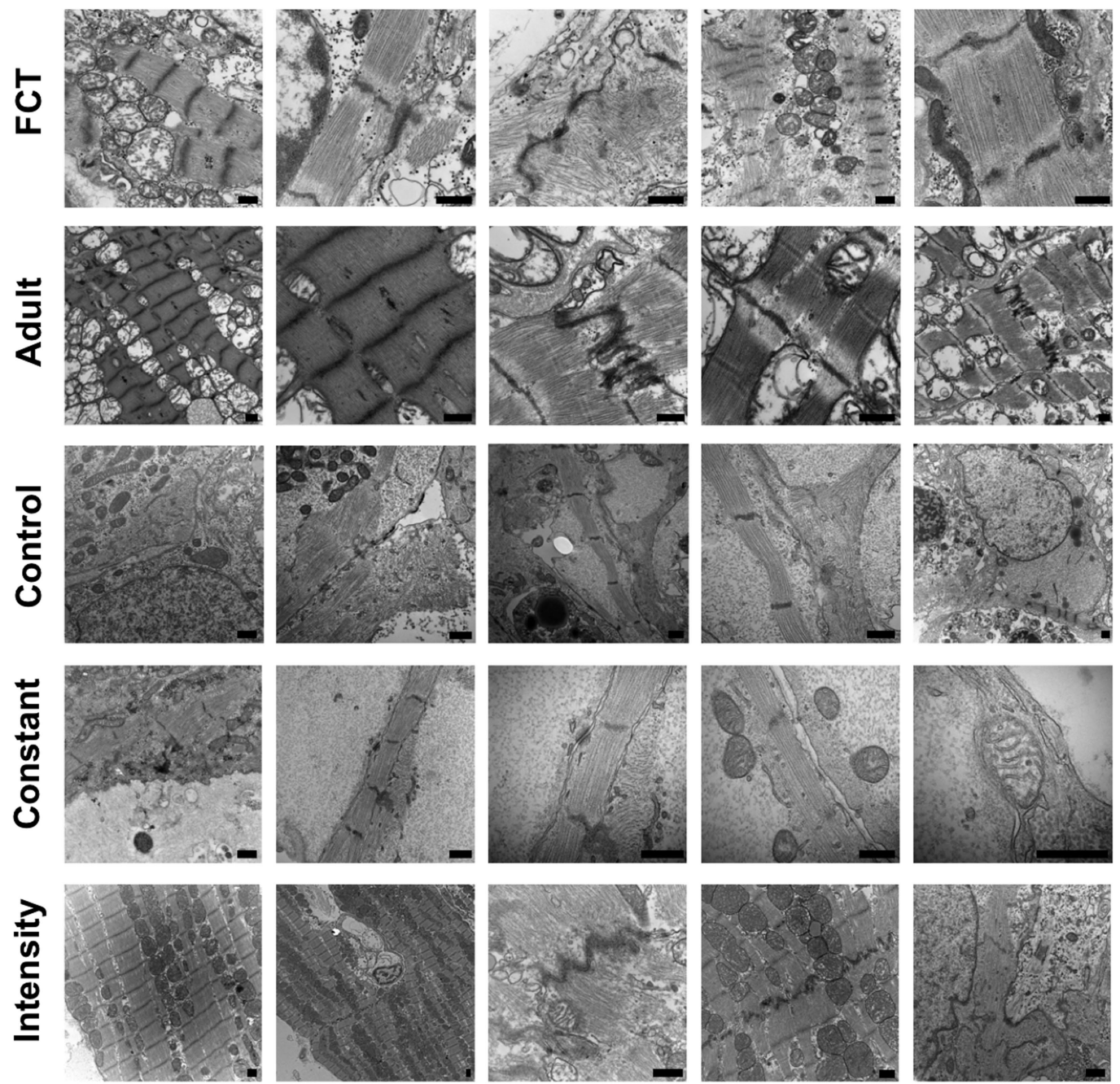

b
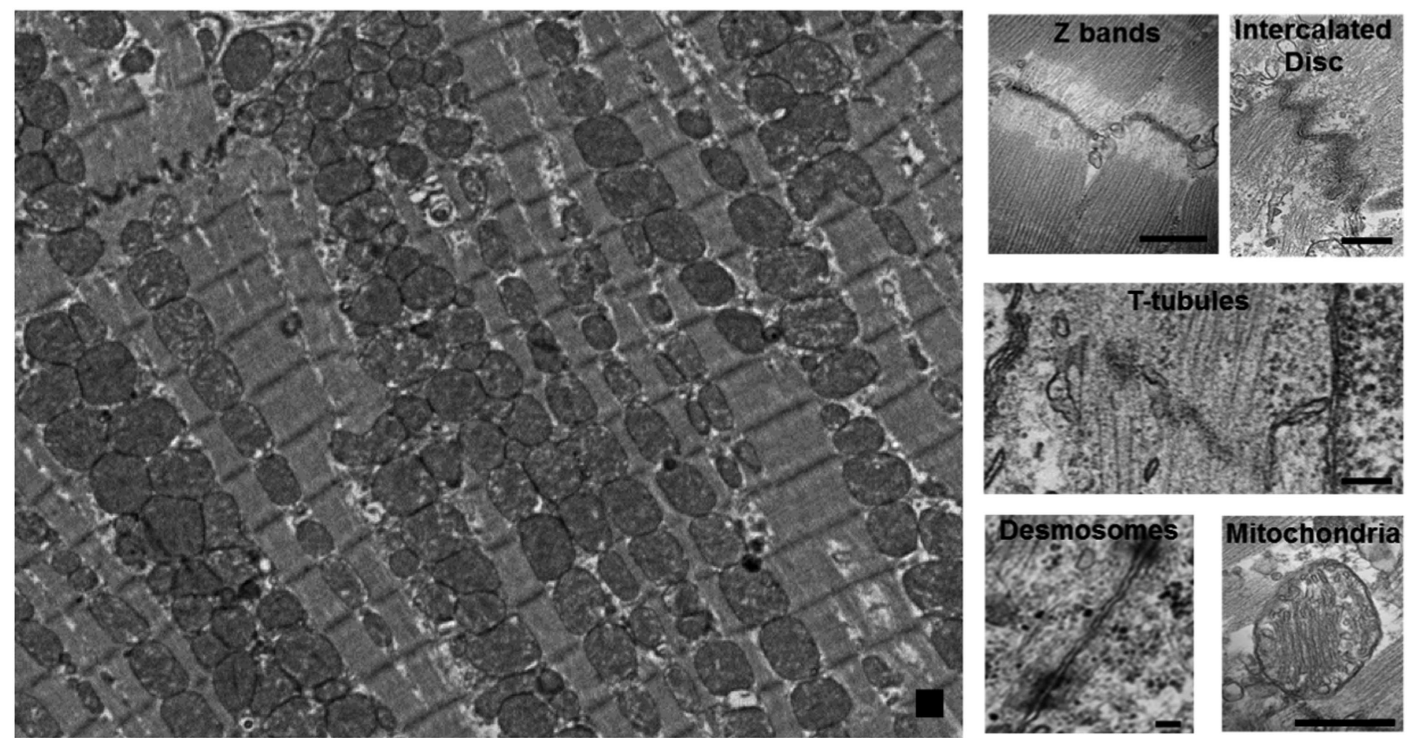

Extended Data Fig. 6 | Enhanced ultrastructural properties of cardiac tissues following intensity training. a, Representative transmission

electron microscopy images for FCTs, adult cardiac tissue, and early-stage cardiac tissues (C2A line) using different electromechanical conditioning protocols, after four weeks of culture. Scale bar, $500 \mathrm{~nm}$. b, TEM images of intensity-trained early-stage cardiac tissues (C2A line) after four weeks of culture showing details of various ultrastructural elements, Scale bar, $500 \mathrm{~nm}$. Similar results to those in $\mathbf{a}$ and $\mathbf{b}$ were obtained independently with the following cells or treatments: FCT $(n=8)$, adult $(n=2)$, control $(n=3)$, constant $(n=3)$, intensity-trained $(n=4)$. 

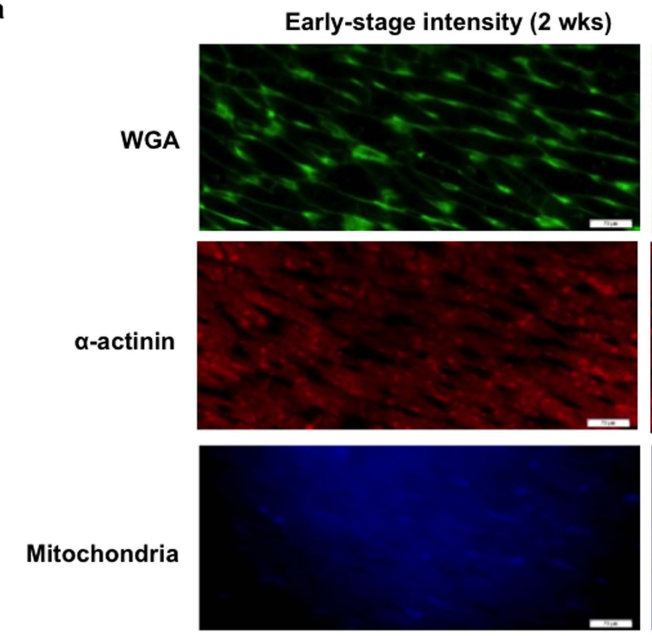

OXPHOS

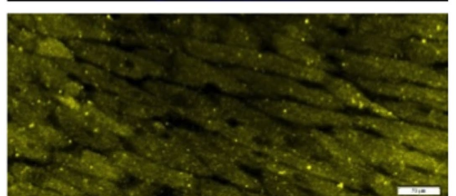

b

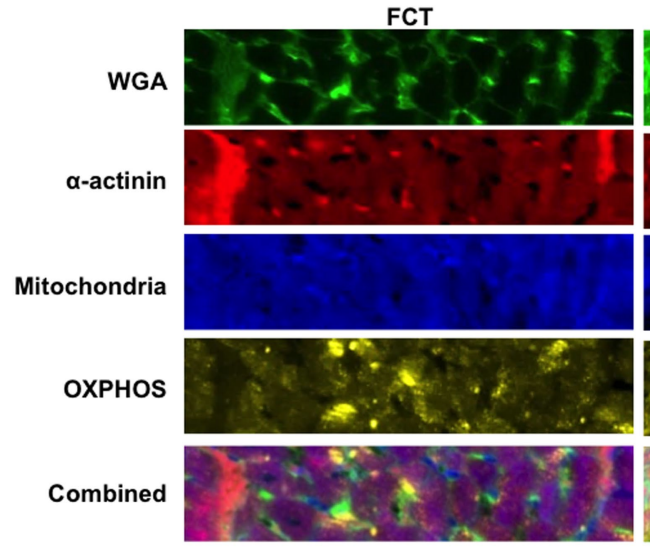

C

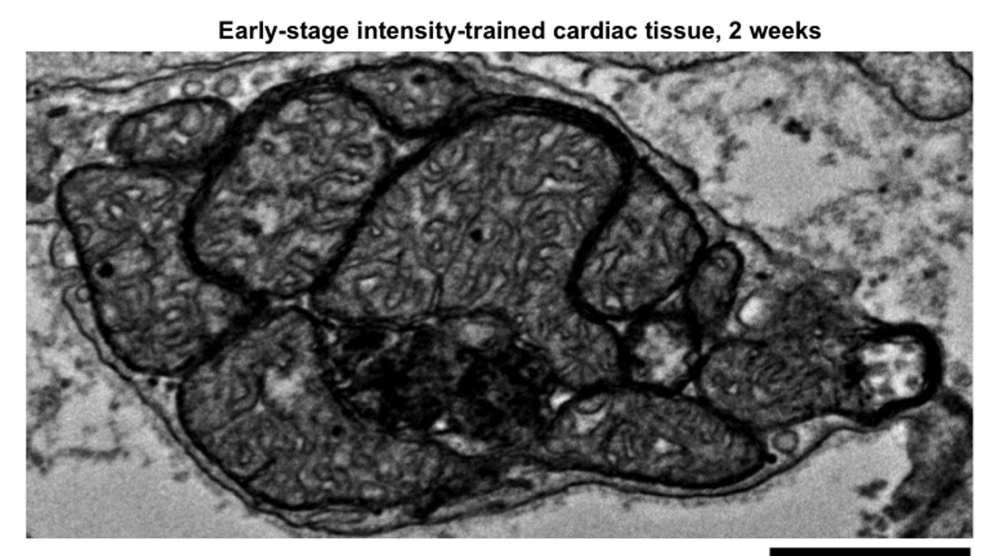

Early-stage intensity (3 wks)
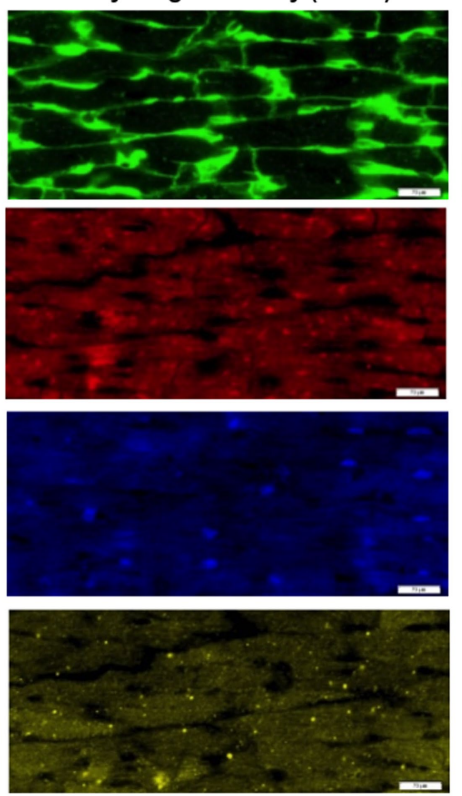

Early-stage intensity
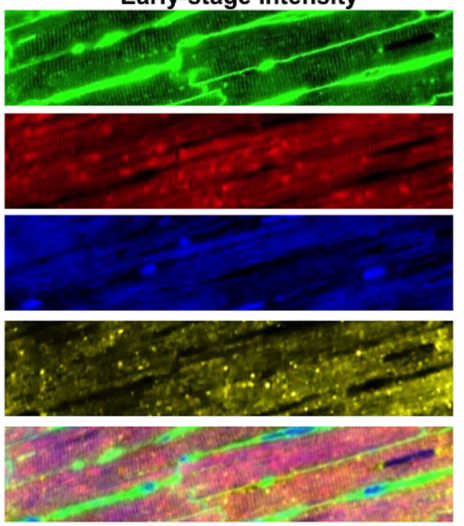

Early-stage intensity (4 wks)
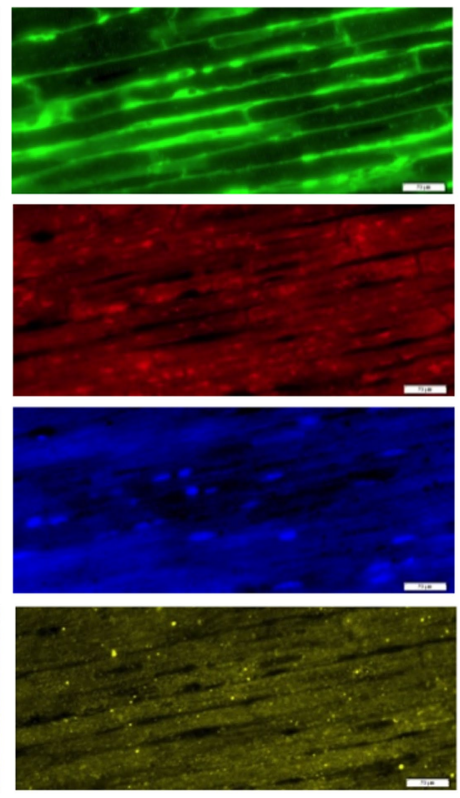

$\therefore$
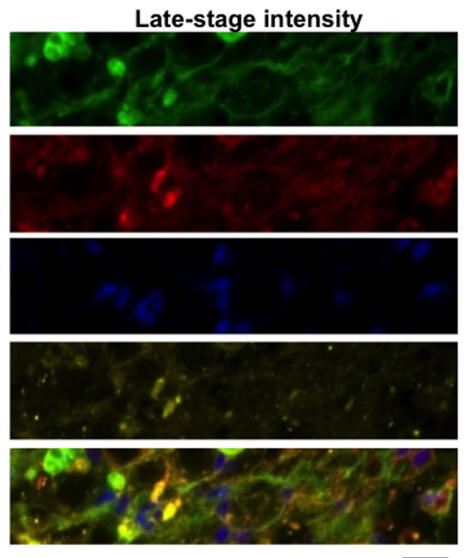

d

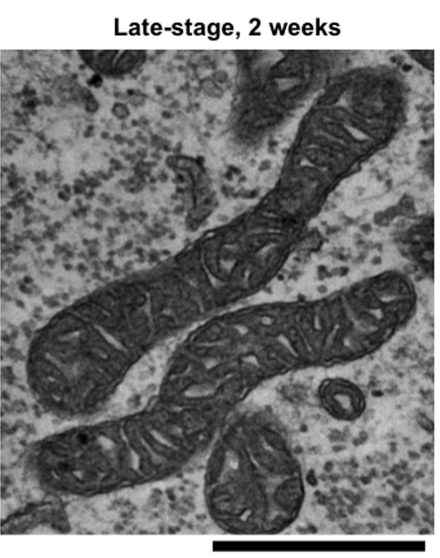

Extended Data Fig. 7 | Intensity training of cardiac tissues derived from early-stage hiPS-CMs is required to enhance mitochondrial development. a, Representative immunofluorescence showing ultrastructural proteins WGA (green), $\alpha$-actinin (red), mitochondria (blue) and oxidative phosphorylation (yellow) for early-stage cardiac tissues (C2A cell line) at different culture times during exposure to the intensity-training electromechanical-conditioning regime. Scale bar, $20 \mu \mathrm{m}$. b. Representative immunofluorescence showing ultrastructural proteins WGA (green), $\alpha$-actinin (red), mitochondria (blue) and oxidative phosphorylation (yellow) in cardiac tissues cultured with intensity training for four weeks from early-stage hiPS-CMs (C2A cell line), latestage hiPS-CMs (C2A cell line) and GW19 FCT. Scale bar, $20 \mu \mathrm{m}$. Similar results to those in $\mathbf{a}$ and $\mathbf{b}$ were obtained independently from the following experiments: FCT $(n=5)$, early-stage intensity-trained $(n=3)$, late-stage intensity-trained $(n=3)$. c, d, Representative TEM images for early-stage (c) and late-stage cardiac tissues (d) (C2A cell line) after two weeks of exposure to the intensity-training electromechanical-conditioning regime. Scale bar, $1 \mu \mathrm{m}$; experiment not repeated independently. 
a

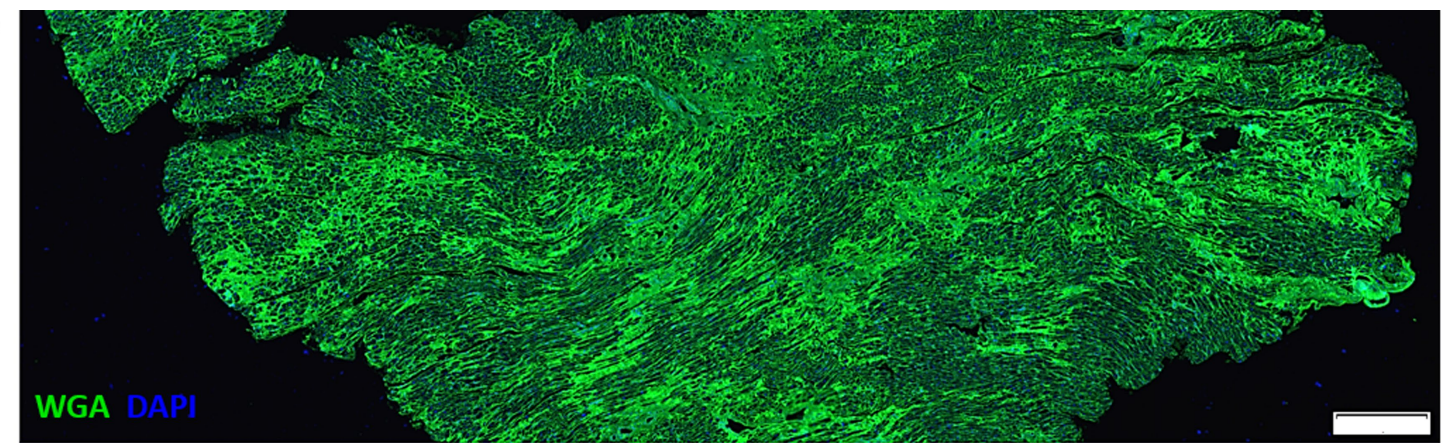

b
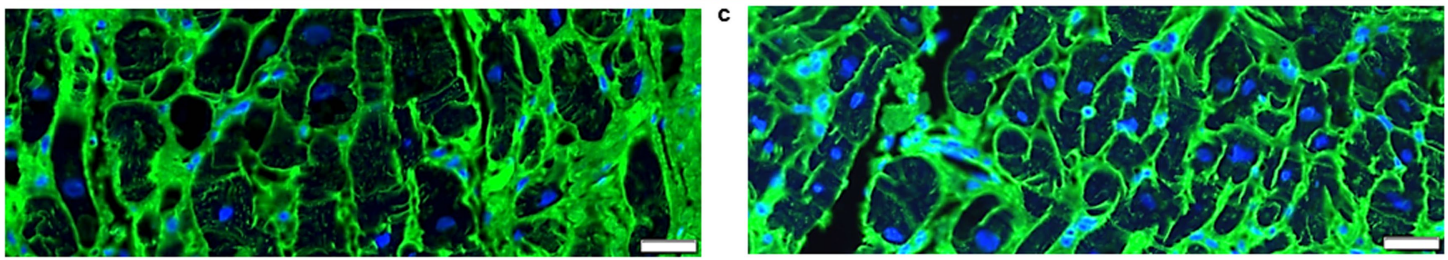

d
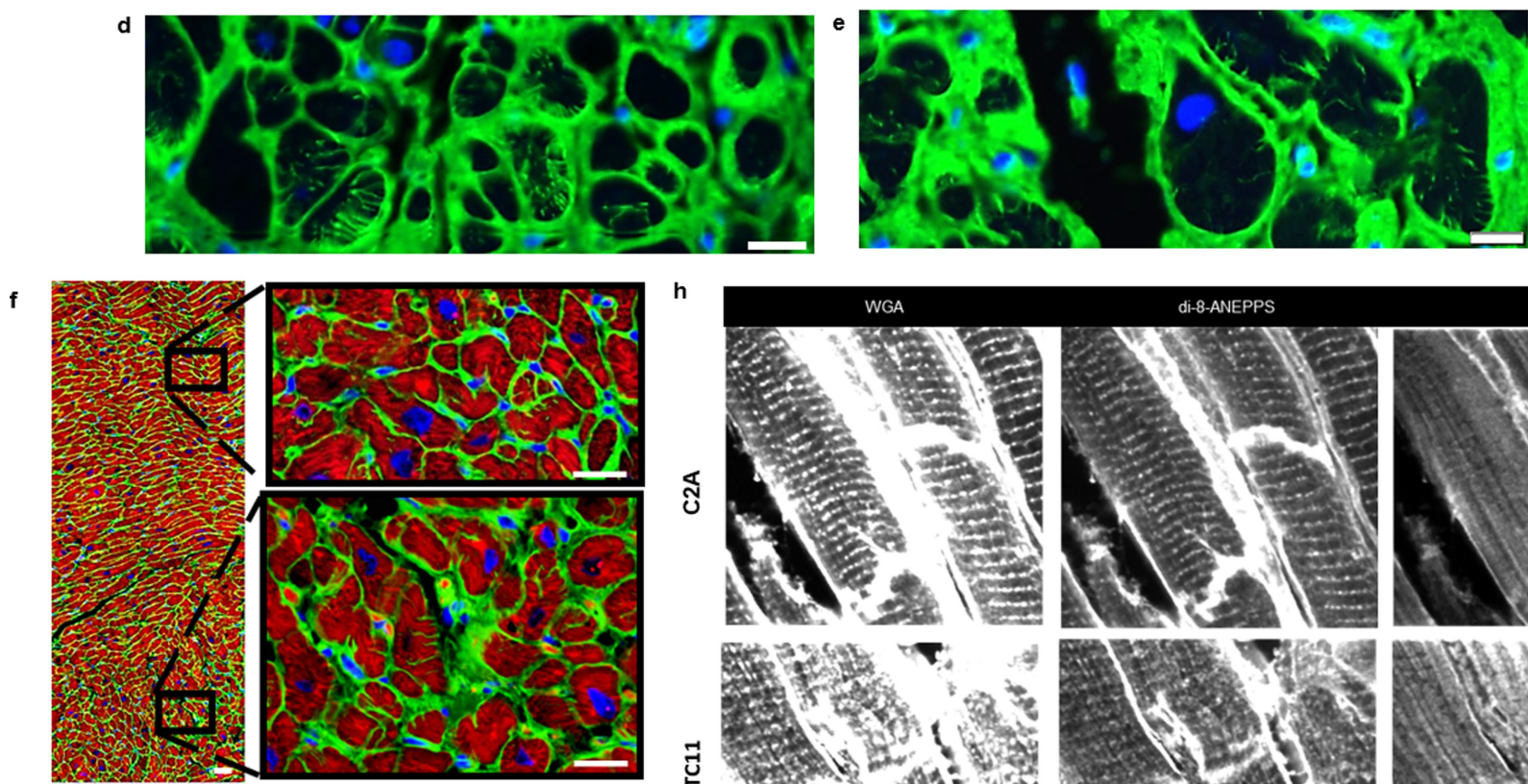

g
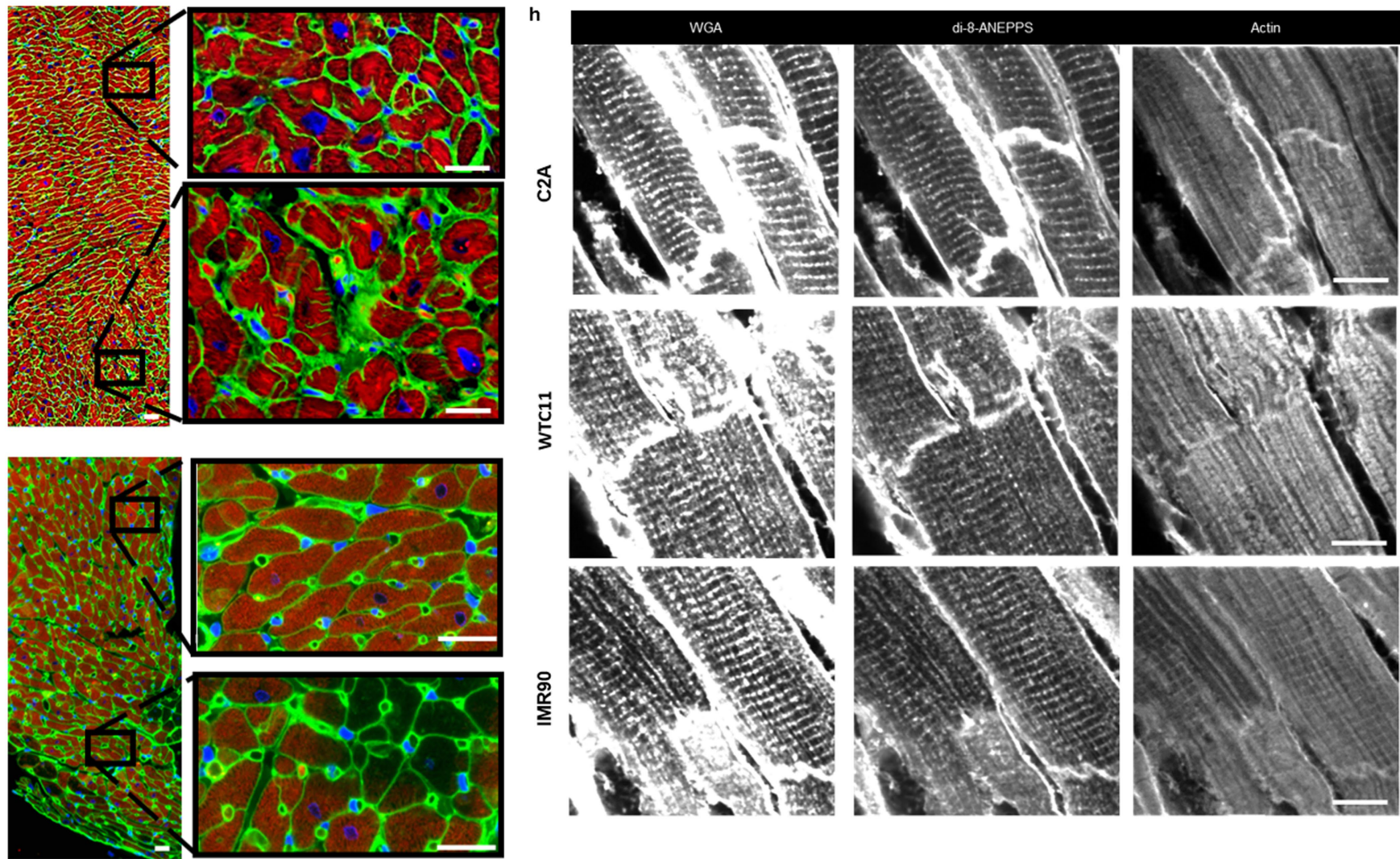

Extended Data Fig. 8 | Formation of T-tubules in early-stage intensitytrained cardiac tissues. a-e, Axial tissue cross-sections from intensitytrained cardiac tissues (C2A line) after four weeks of culture showing T-tubules (WGA, green) and nuclei (DAPI, blue) at low magnification (a; scale bar, $100 \mu \mathrm{m})$, medium magnification (b and c; scale bar, $10 \mu \mathrm{m}$ ) and high magnification (d and e; scale bar, $5 \mu \mathrm{m})$. f, $\mathbf{g}$, Axial tissue crosssections showing T-tubules (WGA, green), actin (red) and DAPI (blue) in intensity-trained cardiac tissues (C2A line) after four weeks of culture (f) and GW19 FCT (g). Scale bar, $10 \mu \mathrm{m}$. h. Immunofluorescence of paraffinembedded and sectioned cardiac tissues from three different iPSC cell lines (C2A, WTC11, IMR90) after four weeks of intensity training showing the formation of T-tubules (confirmed by both WGA staining and di-8-ANEPPS staining), and striated ultrastructure (actin). Scale bar, $10 \mu \mathrm{m}$. Similar results to those in $\mathbf{a}-\mathbf{h}$ were obtained in a minimum of four independent experiments. 

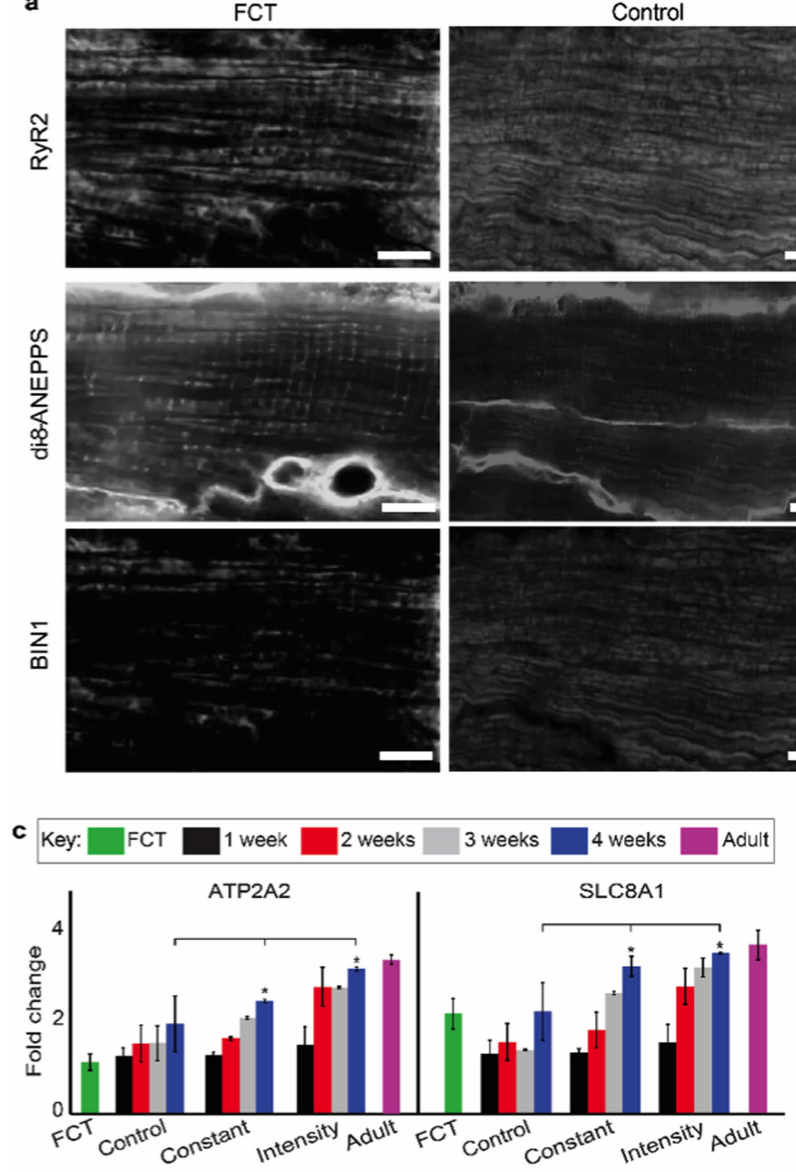

e
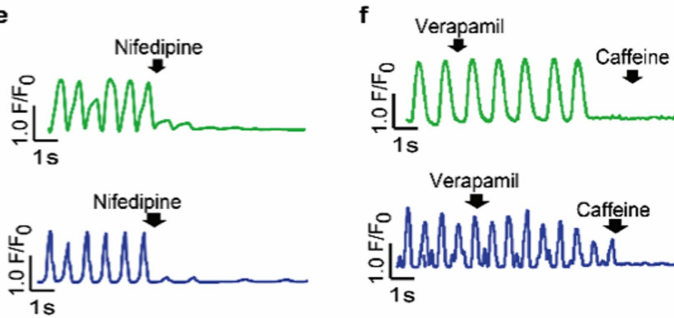

Verapamil
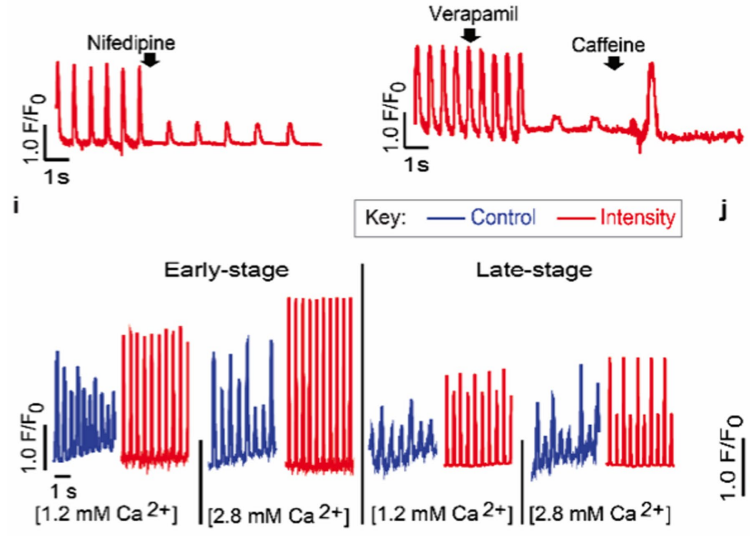

Control
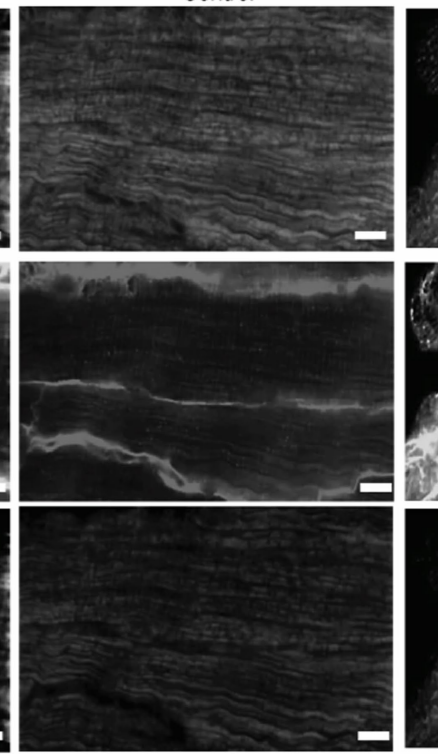
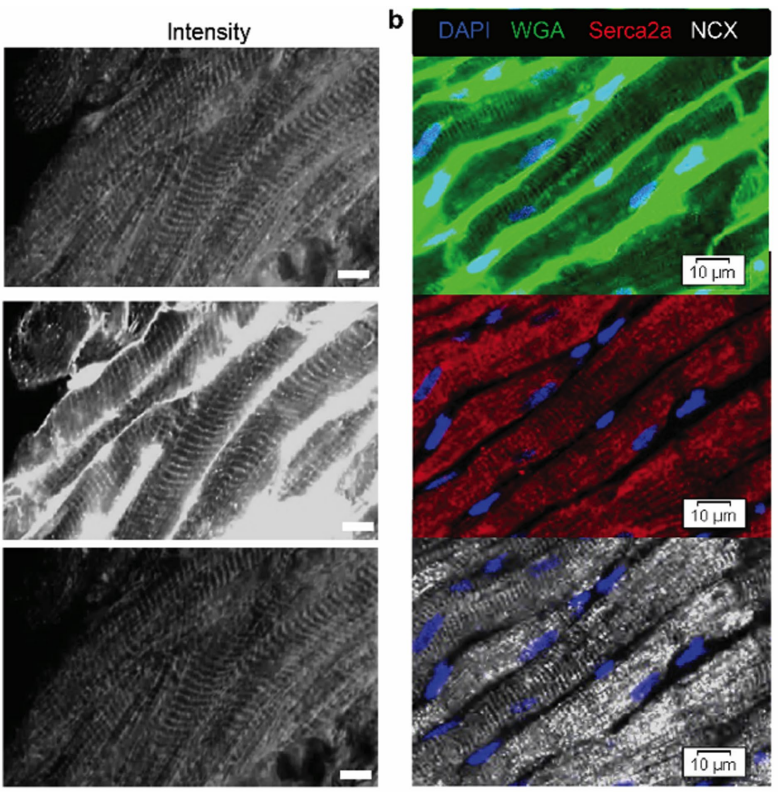
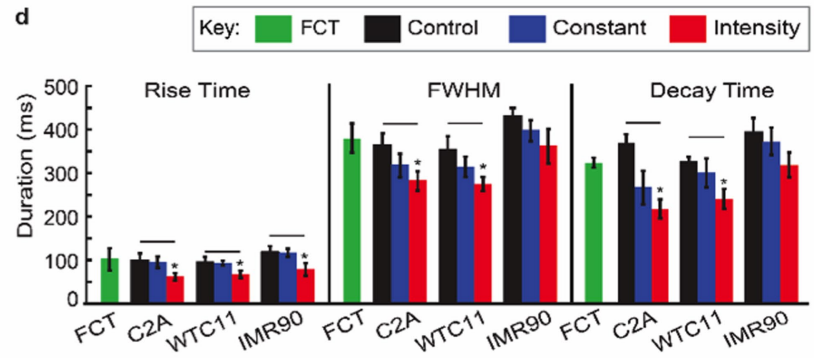

g Thapsigargin

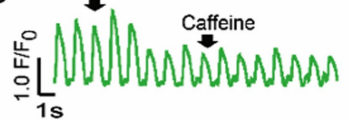

Key: — FCT — Control — Intensity

Thapsigargin

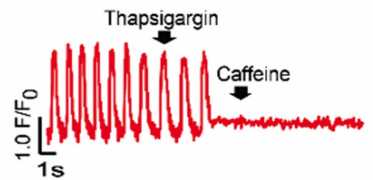

Caffeine

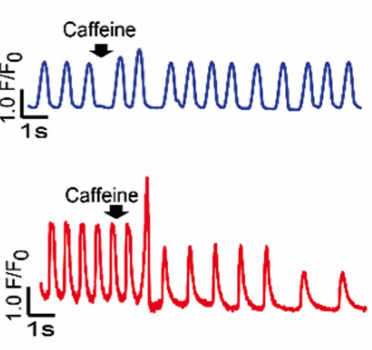

h Caffeine

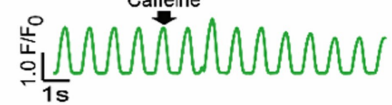

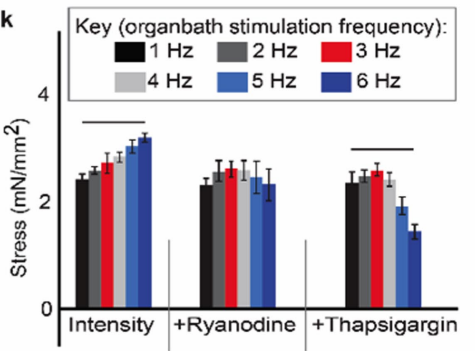

Extended Data Fig. 9 | See next page for caption. 
Extended Data Fig. 9 | Intensity training upregulates cardiac maturation in early-stage tissues through enhanced calcium handling. a, b, Intensity training promotes T-tubule formation in early-stage hiPS-CM tissues, as demonstrated by immunofluorescence of ryanodine 2 receptor (RYR2, green), bridging integrator 1 (BIN1, blue) and T-tubule staining (di-8-ANEPPs, red). Scale bar, $10 \mu \mathrm{m}$. c, Expression of ATP2A2 and $S L C 8 A 1$ genes, which are responsible for maintaining proper calcium homeostasis, in early-stage tissues as determined by RT-PCR and normalized to GAPDH over four weeks of culture with the designated stimulation regime. Independent biological replicates per group: FCT, $n=8$; control, $n=6$; constant, $n=6$; intensity-trained, $n=14$; adult, $n=1$. Mean $\pm 95 \%$ CI, $* P<0.05$ versus FCT group at week four by ANOVA with Tukey's HSD test. Line over graph indicates $P<0.05$ compared to other training regimes by two-way ANOVA with Tukey's HSD test. d, Relaxation times in early-stage tissues as characterized by the full-width half-maximum (FWHM) values and the decay time (90\% of the time from the maximal peak of the calcium transient). Independent biological replicates per group: FCT, $n=8$; C2A, $n=12$; WTC11, $n=6$; IMR90, $n=6$. Mean $\pm 95 \%$ CI; $* P<0.05$ versus FCT group by ANOVA with Tukey's HSD. Line over graph indicates $P<0.05$ between cell lines by twoway ANOVA. e, Representative calcium traces of early-stage tissues treated with $1 \mu \mathrm{M}$ nifedipine. f, $\mathbf{g}$, Representative traces of calcium release after stimulation with $5 \mathrm{mM}$ caffeine in early-stage tissues and FCTs treated with $1 \mathrm{mM}$ verapamil (f) or $2 \mu \mathrm{M}$ thapsigargin (g). h. Representative traces of calcium release after stimulation with $5 \mathrm{mM}$ caffeine for early-stage tissues and FCTs. $\mathbf{i}$, Calcium spikes detected by fluorescent calcium dyes in early and late-stage tissues (C2A line) after four weeks of culture at two calcium concentrations. $\mathrm{j}$, Intensity-trained early-stage but not latestage tissues (C2A line) after four weeks of culture respond to ryanodine $\left(1 \mu \mathrm{mol} \mathrm{l}^{-1}\right)$. $\mathbf{k}$, The force-frequency relationship of early-stage intensitytrained cardiac tissues (C2A line) after four weeks of culture, treated with the RYR2 blocker ryanodine $(1 \mu \mathrm{M})$ or the SERCA2a blocker thapsigargin $(1 \mu \mathrm{M})$. Directly measured force data; $n=13$ biologically independent samples for intensity group and $n=3$ biologically independent samples for other groups. Mean $\pm 95 \% \mathrm{CI}$, line over graph indicates $P<0.05$ by twoway ANOVA. 


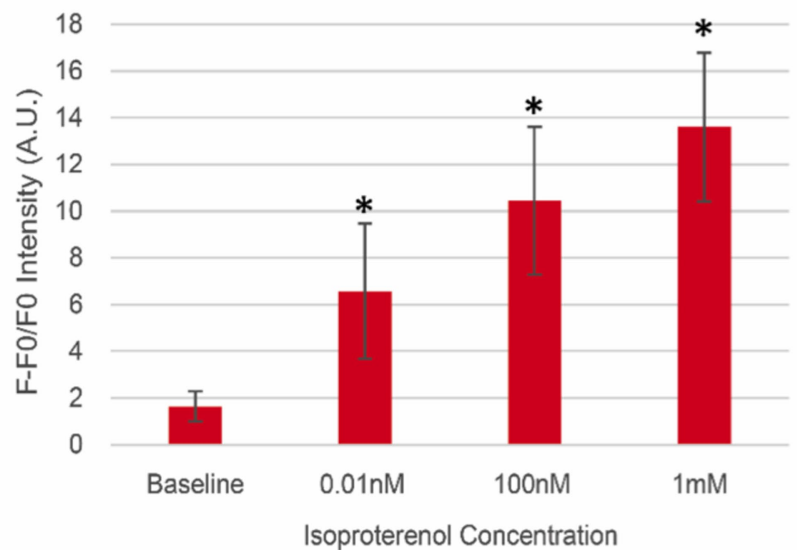

b

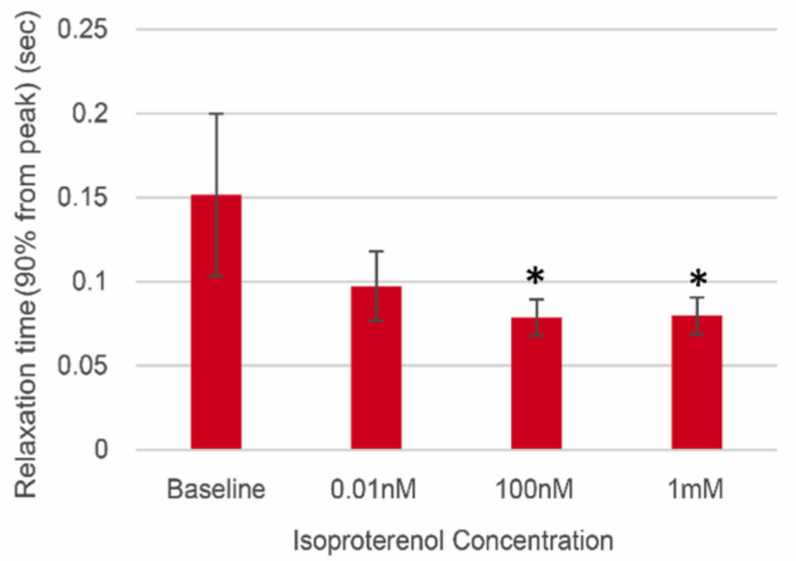

C

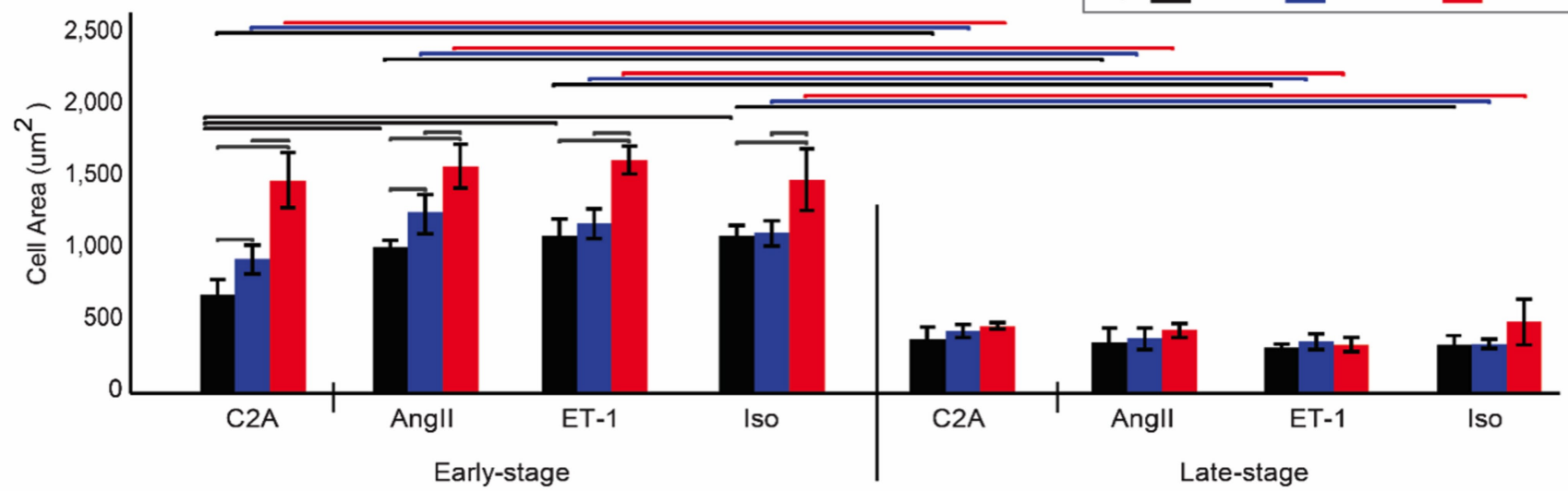

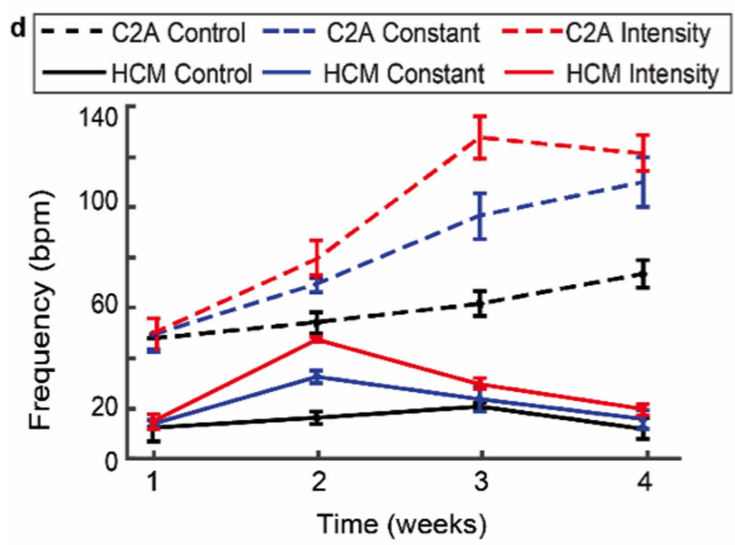

Extended Data Fig. 10 | Intensity training in early-stage tissues enables physiologically relevant drug responses and the development of a pathological hypertrophy disease model. a, b, Calcium intensity measurements (a) and relaxation time obtained by measuring the time from the peak to $90 \%$ of the relaxation (R90) during electrical pacing (b) at $1 \mathrm{~Hz}$ in early-stage intensity-trained tissues (C2A line) after four weeks of culture with increasing doses of isoproterenol. $n=20$ biological replicates from six independent experiments. Mean $\pm 95 \% \mathrm{CI}$; $* P<0.05$ versus baseline response by ANOVA with Tukey's HSD test. c, Cell area over four weeks of culture for the designated stimulation regime. $n=10$ biological replicates from five independent experiments. Mean $\pm 95 \% \mathrm{CI}$; line above graph indicates $P<0.05$ compared to other training regimes by two-way
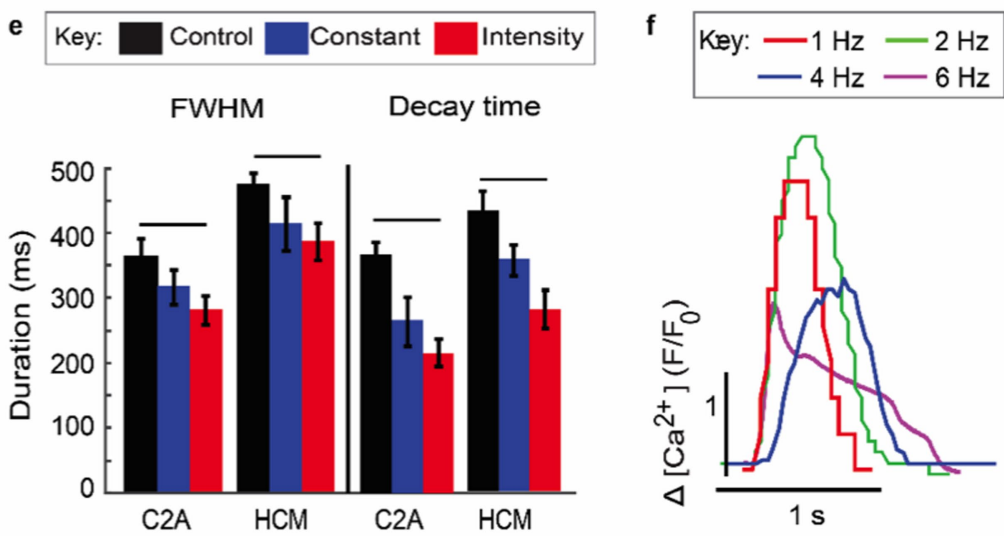

ANOVA with Tukey's HSD test. d, Frequency of contractions in healthy (C2A) and hypertrophic (HCM) heart tissues over four weeks of culture. $n=12$ independent biological samples from five independent experiments. Mean $\pm 95 \%$ CI. e, Relaxation times in early-stage tissues (C2A line) and early-stage hypertrophy tissues (HCM) as characterized by FWHM values and the decay time ( $90 \%$ of the time from the maximal peak of the calcium transient). $n=20$ biological replicates from four independent experiments. Mean $\pm 95 \% \mathrm{CI}$; line above graphs indicate $P<0.05$ compared to other training regimes by two-way ANOVA with Tukey's HSD test. f, Early-stage intensity-trained hypertrophy tissues exhibit impaired FDAR, as shown for each stimulation frequency by individual traces of calcium peaks. 


\section{natureresearch}

\section{Life Sciences Reporting Summary}

Nature Research wishes to improve the reproducibility of the work that we publish. This form is intended for publication with all accepted life science papers and provides structure for consistency and transparency in reporting. Every life science submission will use this form; some list items might not apply to an individual manuscript, but all fields must be completed for clarity.

For further information on the points included in this form, see Reporting Life Sciences Research. For further information on Nature Research policies, including our data availability policy, see Authors \& Referees and the Editorial Policy Checklist.

Please do not complete any field with "not applicable" or n/a. Refer to the help text for what text to use if an item is not relevant to your study. For final submission: please carefully check your responses for accuracy; you will not be able to make changes later.

\section{- Experimental design}

1. Sample size

Describe how sample size was determined.

Initial sample size per experiment was determined based on preliminary studies, and were different for different types of assays, as necessary to achieve statistical significance of data. Statistical methods were not used to predetermine sample size. Instead, sample sizes were chosen to include a minimum of $n=3$ independent biological replicates per experiment, and multiple independent experiments were performed. To further verify the experimental results, the experiments were repeated using three iPS cell lines from three different donors.

2. Data exclusions

Describe any data exclusions.

No data were excluded from the analyses.

3. Replication

Describe the measures taken to verify the reproducibility of the experimental findings.

A total of 253 independently grown cardiac tissues were analyzed, with 12-94 tissues per experimental group, and excellent reproducibility of the experiments.

\section{Randomization}

Describe how samples/organisms/participants were allocated into experimental groups.

\section{Blinding}

Describe whether the investigators were blinded to group allocation during data collection and/or analysis.

The investigators as well as the facilities providing specific analytical assessments were blinded to experimental group allocation.

Note: all in vivo studies must report how sample size was determined and whether blinding and randomization were used.

\section{Statistical parameters}

For all figures and tables that use statistical methods, confirm that the following items are present in relevant figure legends (or in the Methods section if additional space is needed).

n/a $\mid$ Confirmed

The exact sample size $(n)$ for each experimental group/condition, given as a discrete number and unit of measurement (animals, litters, cultures, etc.)

A description of how samples were collected, noting whether measurements were taken from distinct samples or whether the same sample was measured repeatedly

A statement indicating how many times each experiment was replicated

The statistical test(s) used and whether they are one- or two-sided

Only common tests should be described solely by name; describe more complex techniques in the Methods section.

A description of any assumptions or corrections, such as an adjustment for multiple comparisons

Test values indicating whether an effect is present

Provide confidence intervals or give results of significance tests (e.g. P values) as exact values whenever appropriate and with effect sizes noted.

A clear description of statistics including central tendency (e.g. median, mean) and variation (e.g. standard deviation, interquartile range)

Clearly defined error bars in all relevant figure captions (with explicit mention of central tendency and variation) 
Policy information about availability of computer code

\section{Software}

Describe the software used to analyze the data in this study.

All software packages used in the study (e.g., for the measurements of force, contractility, and calcium responses) is specified in the Methods. The commercial or open source software included LabChart 8, Matlab 2014b, and GraphPad Prism 5. The custom-developed software will be made available to other investigators if requested.

For manuscripts utilizing custom algorithms or software that are central to the paper but not yet described in the published literature, software must be made available to editors and reviewers upon request. We strongly encourage code deposition in a community repository (e.g. GitHub). Nature Methods guidance for providing algorithms and software for publication provides further information on this topic.

\section{- Materials and reagents}

Policy information about availability of materials

\section{Materials availability}

Indicate whether there are restrictions on availability of unique materials or if these materials are only available for distribution by a third party.

\section{Antibodies}

Describe the antibodies used and how they were validated for use in the system under study (i.e. assay and species).

\section{Eukaryotic cell lines}

a. State the source of each eukaryotic cell line used.

b. Describe the method of cell line authentication used.

c. Report whether the cell lines were tested for mycoplasma contamination.

d. If any of the cell lines used are listed in the database of commonly misidentified cell lines maintained by ICLAC, provide a scientific rationale for their use.
There are no restrictions, all materials used in the study are available.

All antibodies and their sources are specifically described in the table within the "Immunofluorescent staining" section of the Methods.

Three lines of human induced pluripotent stem cells (iPS cells) were used in the experiments. These cell lines were obtained through Material Transfer Agreements from Stephen Duncan, University of Wisconsin (C2A line), Bruce Conklin, Gladstone Institute (WT11 line) and Masayuki Yazawa, Columbia University (IMR90 line).

All iPS lines we have used are well characterized and published. The autheticity of these lines and their derivatives (iPS-cardiomyocytes) were further confirmed by monitoring marker expression and conducting functional assays. This was also the method for assuring reproducibility of the experiments over 4 years of duration of the study.

The cells were regularly tested for mycoplasma (by PCR) and karyotype.

No commonly misidentified cells were used.

\section{- Animals and human research participants}

Policy information about studies involving animals; when reporting animal research, follow the ARRIVE guidelines

\section{Description of research animals}

Provide all relevant details on animals and/or No animals were used. animal-derived materials used in the study.

Policy information about studies involving human research participants

\section{Description of human research participants}

Describe the covariate-relevant population characteristics of the human research participants.

There were no human research participants in the study. 